\title{
Gas exchange and ventilation-perfusion relationships in the lung
}

\author{
Johan Petersson ${ }^{1,2}$, Robb W. Glenny $y^{3,4}$ \\ Number 7 in the series "Physiology in respiratory medicine" \\ Edited by R. Naeije, D. Chemla, A. Vonk-Noordegraaf and A.T. Dinh-Xuan
}

\begin{abstract}
Affiliations:
'Section of Anaesthesiology and Intensive Care Medicine, Dept of Physiology and Pharmacology, Karolinska Institutet, Stockholm, Sweden.

${ }^{2}$ Dept of Anaesthesiology, Surgical Services and Intensive Care, Karolinska University Hospital, Stockholm, Sweden.

${ }^{3}$ Dept of Medicine, Division of Pulmonary and Critical Care Medicine, University of Washington, Seattle, WA, USA.

${ }^{4}$ Dept of Physiology and Biophysics, University of Washington, Seattle, WA, USA.
\end{abstract}

\section{Correspondence:}

Johan Petersson, Dept of Anaesthesiology, Surgical Services and Intensive Care, Karolinska University Hospital, 17176 Stockholm, Sweden.

E-mail: johan.peterssonakarolinska.se

ABSTRACT This review provides an overview of the relationship between ventilation/perfusion ratios and gas exchange in the lung, emphasising basic concepts and relating them to clinical scenarios. For each gas exchanging unit, the alveolar and effluent blood partial pressures of oxygen and carbon dioxide $\left(\mathrm{PO}_{2}\right.$ and $\left.P \mathrm{CO}_{2}\right)$ are determined by the ratio of alveolar ventilation to blood flow $\left(V^{\prime} \mathrm{A} / Q^{\prime}\right)$ for each unit. Shunt and low $V^{\prime} \mathrm{A} / \mathrm{Q}^{\prime}$ regions are two examples of $V^{\prime} \mathrm{A} / \mathrm{Q}^{\prime}$ mismatch and are the most frequent causes of hypoxaemia. Diffusion limitation, hypoventilation and low inspired $\mathrm{PO}_{2}$ cause hypoxaemia, even in the absence of $V^{\prime} \mathrm{A} / \mathrm{Q}^{\prime}$ mismatch. In contrast to other causes, hypoxaemia due to shunt responds poorly to supplemental oxygen. Gas exchanging units with little or no blood flow (high $V^{\prime} \mathrm{A} / Q^{\prime}$ regions) result in alveolar dead space and increased wasted ventilation, i.e. less efficient carbon dioxide removal. Because of the respiratory drive to maintain a normal arterial $\mathrm{PCO}_{2}$, the most frequent result of wasted ventilation is increased minute ventilation and work of breathing, not hypercapnia. Calculations of alveolar-arterial oxygen tension difference, venous admixture and wasted ventilation provide quantitative estimates of the effect of $V^{\prime} \mathrm{A} / Q^{\prime}$ mismatch on gas exchange. The types of $V^{\prime} \mathrm{A} / \mathrm{Q}^{\prime}$ mismatch causing impaired gas exchange vary characteristically with different lung diseases.

@ERSpublications

A review of ventilation-perfusion relationships and gas exchange, basic concepts and their relation to clinical cases http://ow.ly/wMUwq

Previous articles in this series: No 1: Naeije R, Vachiery J-L, Yerly P, et al. The transpulmonary pressure gradient for the diagnosis of pulmonary vascular diseases. Eur Respir J 2013; 41: 217-223. No. 2: Hughes JMB, van der Lee I. The TL,NO/ TL,CO ratio in pulmonary function test interpretation. Eur Respir J 2013; 41: 453-461. No. 3: Vonk-Noordegraaf A, Westerhof N. Describing right ventricular function. Eur Respir J 2013; 41: 1419-1423. No. 4: Hamzaoui O, Monnet X, Teboul J-L. Pulsus paradoxus. Eur Respir J 2013; 42: 1696-1705. No. 5: Prisk GK. Microgravity and the respiratory system. Eur Respir J 2014; 43: 1459-1471. No. 6: Dempsey JA, Smith CA. Pathophysiology of human ventilatory control. Eur Respir J 2014; 44: 495-512.

Received: Feb 242014 | Accepted after revision: May 042014 | First published online: July 242014

Conflict of interest: None declared

Copyright (OERS 2014 


\section{Introduction}

While the healthy lung efficiently exchanges respiratory gases, hypoxaemia and hypercapnia indicate pathophysiology and failure of the lung to provide adequate gas exchange. An understanding of how gases are transferred and the causes of inefficient gas exchange are central to caring for patients with lung diseases. In this article, we will review the normal and pathological mechanisms of gas exchange. Starting with simple and building to more complex, we will emphasise basic concepts and relate them to case scenarios familiar to clinicians.

\section{Lung structure}

The structure of the lung is well suited for efficient exchange of respiratory gases. Through the airway and vascular trees, fresh gases and venous blood are delivered to and removed from a large alveolar capillary surface area. In an adult, inhaled air enters the trachea with a cross-sectional area of $\sim 3 \mathrm{~cm}^{2}$ and is delivered to the alveoli with a surface area of $\sim 140 \mathrm{~m}^{2}$, roughly the size of a tennis court [1]. Similarly, the pulmonary vascular tree begins as the main pulmonary artery and repeatedly bifurcates into arterioles and capillaries that cover $85-95 \%$ of the alveolar surface [1]. An exceptionally thin membrane of only $1 \mu \mathrm{m}$ $[2,3]$ separates the alveolar gas and blood compartments, allowing gases to diffuse rapidly between them. Due to the relatively large blood volume within the alveolar capillaries, blood flow slows and the transit time for blood increases, normally to $0.25-0.75 \mathrm{~s}$, allowing more time for gas exchange. The remarkable design that allows this gas exchanging system to be constructed within the thoracic cavity has been highlighted by comparing this engineering feat to that of folding a letter so that it fits into a thimble [3].

\section{A single lung unit}

We start with a simple lung model consisting of just one gas exchanging unit (fig. 1a). The capillaries of the unit deliver mixed venous blood with a low partial pressure of $\mathrm{O}_{2}\left(P_{\overline{\mathrm{v}}} \mathrm{O}_{2}\right)$. The partial pressure of $\mathrm{O}_{2}\left(P_{\mathrm{O}_{2}}\right)$ in the alveolar gas $\left(\mathrm{PAO}_{2}\right)$ is much higher than in the capillary blood and $\mathrm{O}_{2}$ diffuses passively from the alveolar space into the blood during passage through the capillaries (fig. 2a). The membrane separating the alveolar gas and blood compartments causes little resistance to diffusion so the $\mathrm{PO}_{2}$ in end-capillary blood $\left(\mathrm{PecO}_{2}\right)$ equilibrates with $\mathrm{PAO}_{2}$ well before the blood leaves the unit. Oxygenation of arterial blood is, therefore, primarily dependent on the $\mathrm{PAO}_{2}$. Note that in this idealised lung unit there is no difference between $P_{\mathrm{AO}_{2}}$ and $\mathrm{PO}_{2}$ in arterial blood $\left(\mathrm{PaO}_{2}\right)$. For reasons explained later, the alveolar-arterial $\mathrm{O}_{2}$ tension difference $\left(\mathrm{PA}_{\mathrm{A}} \mathrm{aO} \mathrm{O}_{2}\right)$ is very helpful when assessing the causes of gas exchange problems in clinical medicine and we will use it throughout this review. While the term "gradient" is also commonly used, we prefer to use "difference" to highlight that the difference between the $\mathrm{PAO}_{2}$ and $\mathrm{PaO}_{2}$ is not due to a pressure gradient between them. The partial pressure of $\mathrm{CO}_{2}\left(P_{C_{2}}\right)$ is greater in mixed venous blood $\left(P_{\overline{\mathrm{V}}} \mathrm{CO}_{2}\right)$ than in the alveolar gas $\left(P_{A C O}\right)$ and diffusion over the alveolar-capillary membrane, therefore, results in a net flow in a direction opposite to that of $\mathrm{O}_{2}$, from blood to alveolar gas (fig. 2b). The result is again an equal $\mathrm{PCO}_{2}$ in alveolar gas and end-capillary blood $\left(\mathrm{PecCO}_{2}\right)$ because the resistance for diffusion is even less for $\mathrm{CO}_{2}$ than for $\mathrm{O}_{2}$. Due to differences in the relationship between partial pressures and blood content for $\mathrm{O}_{2}$ and $\mathrm{CO}_{2}$, there is approximately as much $\mathrm{CO}_{2}$ exchanged for a partial pressure difference between mixed venous and arterial blood of $5 \mathrm{mmHg}(0.7 \mathrm{kPa})$ as there is $\mathrm{O}_{2}$ exchanged with a difference of $60 \mathrm{mmHg}(6.7 \mathrm{kPa})$. The amount of $\mathrm{O}_{2}$ carried in the blood is determined by the haemoglobin concentration, the fraction of haemoglobin binding $\mathrm{O}_{2}$ and the $\mathrm{PaO}_{2}$ (fig. 1b). When we discuss multiple lung unit models below, it is important to understand that the end-capillary blood $\mathrm{O}_{2}$ content $\left(\mathrm{CecO}_{2}\right)$, rather than the $\mathrm{PecO}_{2}$, from different units are additive.

\section{Five causes of arterial hypoxaemia}

A single-unit model (fig. 1a) is used to begin our discussion of five potential causes of hypoxaemia as well as hypercapnia. Our first example is one of diffusion limitation.

\section{Diffusion limitation}

In case 1, a 25-year-old male elite cyclist who undergoes a cardiopulmonary exercise study is noted to have progressively worsening arterial hypoxaemia with increasing workload (a response not seen in normal individuals). Arterial blood gases (ABGs) at end-exercise are: $\mathrm{pH} 7.18, \mathrm{PCO}_{2}$ in arterial blood $\left(\mathrm{PaCO}_{2}\right)$ $30 \mathrm{mmHg}(4.0 \mathrm{kPa}), \mathrm{PaO}_{2} 81 \mathrm{mmHg}(10.8 \mathrm{kPa})$ and arterial haemoglobin $\mathrm{O}_{2}$ saturation $88 \%$.

Exercise increases the amount of $\mathrm{O}_{2}$ extracted from arterial blood in the systemic circulation, which tends to reduce $P_{\overline{\mathrm{v}}} \mathrm{O}_{2}$. Therefore, more $\mathrm{O}_{2}$ needs to be taken up in the lung to reach normal oxygenation of arterial blood. Exercise also increases pulmonary blood flow, which shortens the time that the blood is exposed to alveolar gas. The combined effect is that more $\mathrm{O}_{2}$ needs to be taken up in less time (fig. 3). At very high cardiac outputs, the transit time might be too short for complete equilibration between $\mathrm{PAO}_{2}$ and $\mathrm{PecO}_{2}$. This represents diffusion limitation as a cause of hypoxaemia in athletes achieving extremely high cardiac 


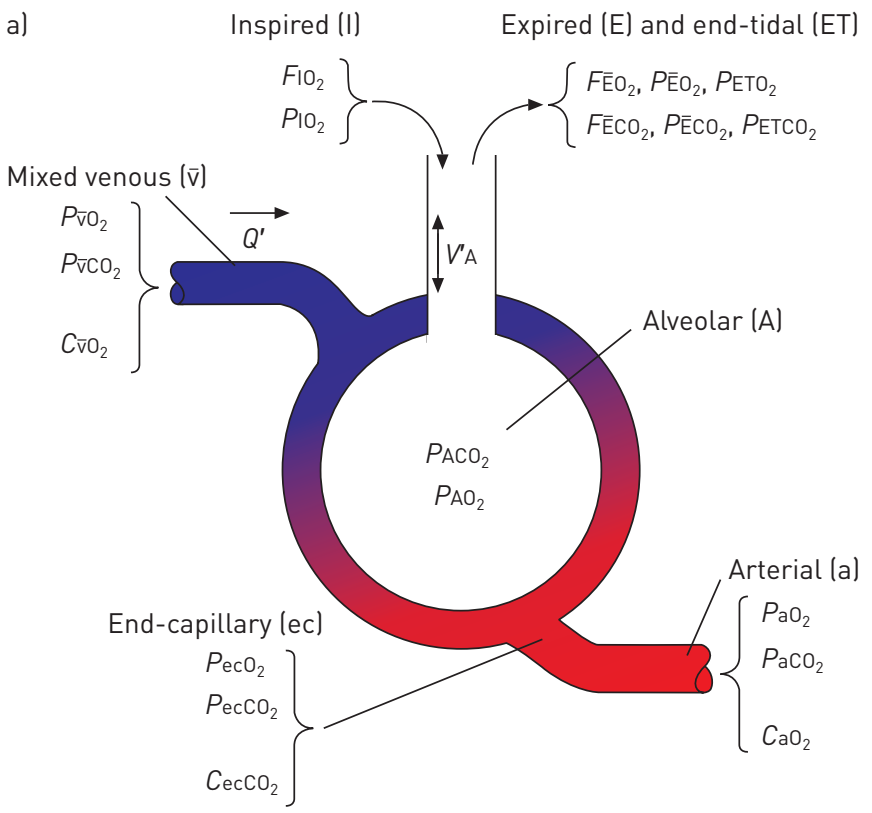

b)

FIGURE 1 a) An illustration of the notations used for partial pressures, fractions of gas and $\mathrm{O}_{2}$ content for different compartments in a single lung unit, as defined in table 1 . Note that with a single-unit lung model, arterial and end-capillary values are equal. b) The haemoglobin-oxygen $\left(\mathrm{Hb}-\mathrm{O}_{2}\right)$ dissociation curve for partial pressure of $\mathrm{O}_{2}\left(\mathrm{PO}_{2}\right), \mathrm{O}_{2}$ saturations and $\mathrm{O}_{2}$ content in the venous and arterial compartments for a haemoglobin concentration of $15 \mathrm{~g} \cdot \mathrm{dL}^{-1}$.

outputs [4-6]. Hypoxaemia due to diffusion limitation can also be seen in normal individuals during exercise at altitude. In this setting, the driving pressure for $\mathrm{O}_{2}$ diffusion is decreased due to the lower $\mathrm{PO}_{2}$ in inspired air $\left(\mathrm{PIO}_{2}\right)$ at altitude and the transit time of blood through the alveolar capillaries is shorter due to higher cardiac outputs. A diffusion limitation can also occur in patients with interstitial lung diseases. Patients with these diseases might have a normal $\mathrm{PaO}_{2}$ at rest but develop hypoxaemia during exercise, which can be explained by the combined effect of increased resistance to diffusion through the thickened alveolar-capillary membrane, reduced $P_{\overline{\mathrm{v}}} \mathrm{O}_{2}$ and a shortened transit time [7].

Diffusion limitation is one of five causes of hypoxaemia (table 2). The lack of equilibration between $\mathrm{PAO}_{2}$ and $\mathrm{PecO}_{2}$ creates an increased $\mathrm{PA}-\mathrm{aO}_{2}$. Hypoxaemia in these patients, as a rule, responds nicely to supplemental $\mathrm{O}_{2}$. While this does not correct the diffusion limitation, it raises the $\mathrm{PAO}_{2}$ and the driving

\section{TABLE 1 Glossary of gas variables and other notations}

\section{Variable Definition and (units)}

\section{Possible compartments $X$}

\section{Examples of gas $Y$}

$\begin{array}{ll}\mathbf{P X Y} & \text { Partial pressure of gas } Y \text { in compartment } X(\mathrm{mmHg} \text { or } \mathrm{kPa} \text { ) } \\ \mathbf{F X Y} & \text { Fraction of gas } Y \text { in compartment } X \text { (decimal or } \% \text { ) } \\ \mathbf{C X Y} & \text { Content of gas } Y \text { in compartment } X(\mathrm{~mL} \text { per } 100 \mathrm{~mL} \text { of blood) } \\ \mathbf{S x O}_{2} & \text { Haemoglobin-oxygen saturation in compartment } X(\%)\end{array}$

$\mathrm{B}=$ barometric

$\mathrm{I}=$ inspired gas

$\mathrm{E}=$ expired gas

$\overline{\mathrm{E}}=$ mixed expired gas

$\mathrm{ET}=$ end-tidal

$\mathrm{A}=$ alveolar gas

$\mathrm{a}=$ arterial blood

$\mathrm{c}=$ capillary

ec $=$ end-capillary blood

$\overline{\mathrm{v}}=$ mixed venous blood

\begin{tabular}{|c|c|c|}
\hline$V^{\prime} \mathbf{x}$ & Ventilation $\left(\mathrm{mL} \cdot \mathrm{min}^{-1}\right)$ in compartment $\mathrm{X}$ & $\begin{array}{l}\mathrm{A}=\text { alveolar } \\
\mathrm{D}=\text { dead space }\end{array}$ \\
\hline$Q^{\prime} \mathbf{X}$ & Blood flow $\left(\mathrm{mL} \cdot \mathrm{min}^{-1}\right)$ in compartment $X$ & $\begin{array}{l}\mathrm{t}=\text { total } \\
\mathrm{s}=\text { shunt }\end{array}$ \\
\hline$V^{\prime} \mathrm{A} / Q^{\prime}$ & Regional ratio of alveolar ventilation to perfusion (unitless) & \\
\hline $\mathbf{V x}$ & Volume (mL) in compartment $X$ & $\begin{array}{l}\mathrm{T}=\text { tidal } \\
\mathrm{D}=\text { dead space }\end{array}$ \\
\hline
\end{tabular}

$\mathrm{O}_{2}$ $\mathrm{CO}_{2}$ $\mathrm{H}_{2} \mathrm{O}$ 
a)
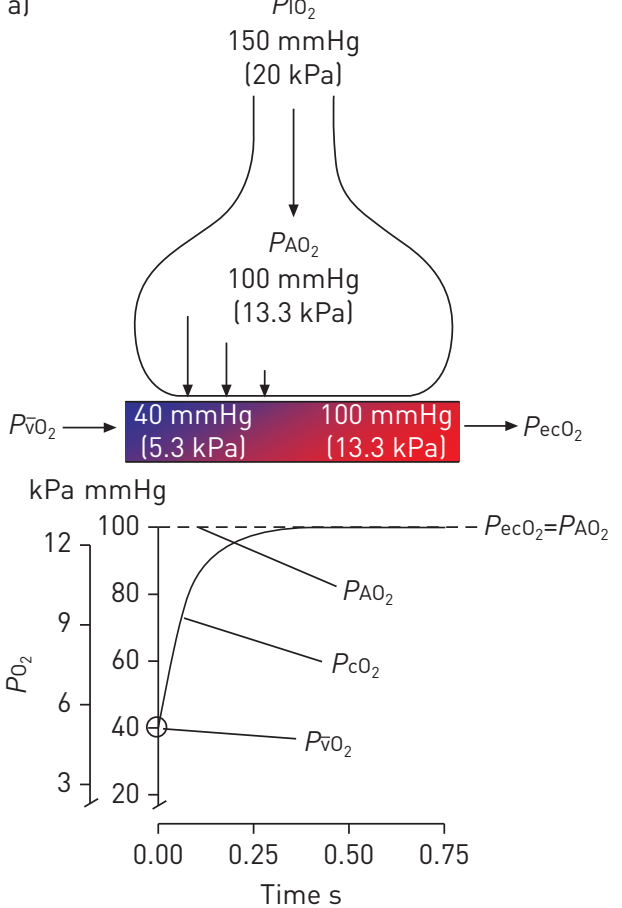

b)
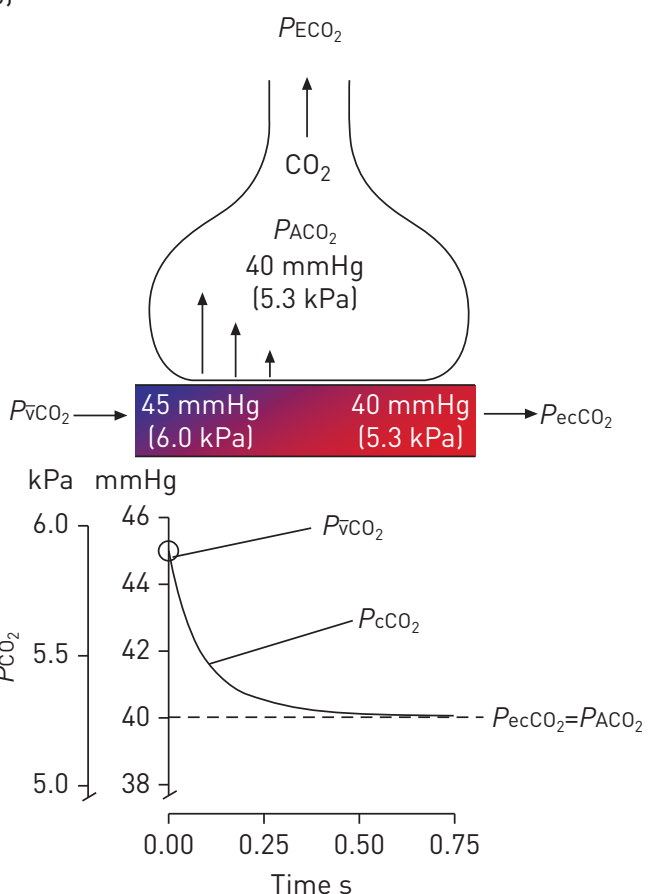

FIGURE 2 a) $\mathrm{PO}_{2}$ in different compartments and how diffusion of $\mathrm{O}_{2}$ along the capillary allows $P_{\mathrm{ecO}}$ to equal $P_{\mathrm{AO}}$ well before the blood leaves the unit. Note that the result is a $\mathrm{PA}_{\mathrm{A}-\mathrm{aO}}$ of zero. b) $\mathrm{PCO}_{2}$ illustrated in a similar manner. The time scale on the diagrams in both panels refers to the transit time for the erythrocytes through the alveolar capillaries, normally $0.25-0.75 \mathrm{~s}$. For a glossary of terms, see table 1 .

pressure for diffusion of $\mathrm{O}_{2}$ into the blood. Due to the low resistance to diffusion of $\mathrm{CO}_{2}, \mathrm{PaCO}_{2}$ is normal in patients with $\mathrm{O}_{2}$ diffusion limitations. Although diffusion limitation is our first cause listed for hypoxaemia in table 2, from a clinical perspective, it is an uncommon reason for a low $\mathrm{PaO}_{2}$.

\section{Hypoventilation}

In case 2, an 82-year-old female with chronic renal failure on continuous ambulatory peritoneal dialysis (CAPD) had recently contracted whooping cough from her grandchildren. Her physician prescribed an

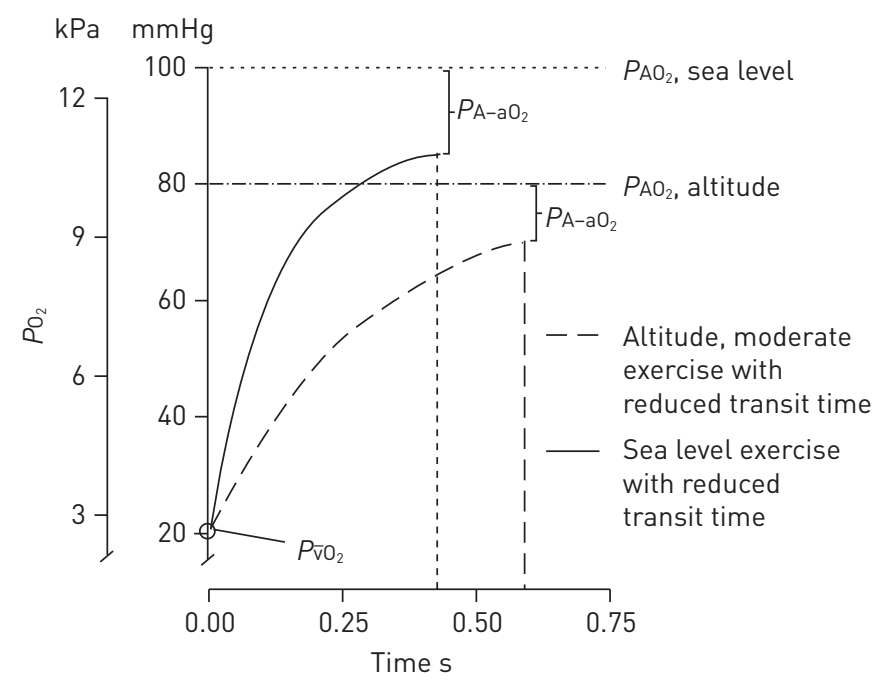

FIGURE 3 Oxygenation of capillary blood as a function of time under different conditions. The panel illustrates how $\mathrm{PecO}_{2}$ and hence $\mathrm{PaO}_{2}$ fail to reach $P_{\mathrm{AO}}$ due to low $P_{\overline{\mathrm{v}}} \mathrm{O}_{2}$ and short transit time during extreme exercise at sea level (solid curve) and moderate exercise at altitude (dashed curve). Compare with the normal rate of oxygenation in figure 2a. For a glossary of terms, see table 1 . 
TABLE 2 Five causes of hypoxaemia

\begin{tabular}{|c|c|c|c|}
\hline Cause of hypoxaemia & $\mathrm{PAO}_{2}$ & $P A-\mathrm{aO}_{2}$ & $\begin{array}{l}\mathrm{PaO}_{2} \text { response to } \\
\text { increased } \mathrm{FIO}_{2}\end{array}$ \\
\hline Diffusion limitation & Normal & Increased & Improved \\
\hline Hypoventilation & Reduced & Normal & Improved \\
\hline Decreased $\mathrm{P}_{10}$ & Reduced & Normal & Improved \\
\hline Low $V^{\prime} A / Q^{\prime}$ & Reduced locally & Increased & Improved \\
\hline Shunt & Reduced locally & Increased & Minimal improvement \\
\hline
\end{tabular}

$P_{A_{2}}$ : alveolar partial pressure of $\mathrm{O}_{2} ; P_{A-a O}$ : alveolar-arterial $\mathrm{O}_{2}$ tension difference; $\mathrm{PaO}_{2}$ : arterial partial pressure of $\mathrm{O}_{2} ; \mathrm{FlO}_{2}$ : inspiratory $\mathrm{O}_{2}$ fraction; $\mathrm{PIO}_{2}$ : partial pressure of $\mathrm{O}_{2}$ in inspired gas; $V^{\prime} \mathrm{A} / \mathrm{Q}^{\prime}$ : ratio of alveolar ventilation to perfusion.

opioid-containing antitussive to reduce the cough. She is now drowsy and unable to manage the CAPD routines. An ABG analysis reveals $\mathrm{pH} 7.17, \mathrm{PaO}_{2} 45 \mathrm{mmHg}(6.0 \mathrm{kPa})$ and $\mathrm{PaCO}_{2} 77 \mathrm{mmHg}(10.3 \mathrm{kPa})$.

This case highlights hypoventilation as a cause of hypoxaemia. Although the quantitative relationship is complex $[8,9]$, it can be intuitively understood that $\mathrm{PAO}_{2}$ in our single alveolar unit (fig. 1a) is influenced by the ratio between $\mathrm{O}_{2}$ delivery (ventilation, $V^{\prime}$ A) and $\mathrm{O}_{2}$ removal (blood flow, $Q^{\prime}$ ). Hence, one of the determinants of $\mathrm{PAO}_{2}$ is the balance or ratio between ventilation and blood flow $\left(V^{\prime} \mathrm{A} / Q^{\prime}\right)$. In the patient from case 2, hypoventilation and normal blood flow results in a low $V^{\prime} \mathrm{A} / \mathrm{Q}^{\prime}$ ratio (less delivery and unchanged removal of $\mathrm{O}_{2}$ ), which lowers $\mathrm{PAO}_{2}$ and consequently $\mathrm{PecO}_{2}$. Conversely, hyperventilation (increased ventilation relative to blood flow) increases $P_{\mathrm{AO}_{2}}$ and $\mathrm{PeCO}_{2} \cdot \mathrm{PACO}_{2}$ is also determined by the $V^{\prime} \mathrm{A} / Q^{\prime}$ ratio but $\mathrm{CO}_{2}$ is delivered through blood flow and $\mathrm{CO}_{2}$ is removed through ventilation, the converse of $\mathrm{O}_{2}$. Hence, a decreased $V^{\prime} \mathrm{A} / Q^{\prime}$ ratio results in higher $P_{\mathrm{ACO}_{2}}$ and $\mathrm{PaCO}_{2}$, the hallmark of hypoventilation, while an increased ratio lowers $\mathrm{PACO}_{2}$. These relationships are illustrated in figure 4 . The balance between $\mathrm{O}_{2}$ delivery and removal results in a $\mathrm{PAO}_{2}$ that can be quantified using the alveolar gas equation (box 1).

Hypoxaemia secondary to hypoventilation is, thus, due to a low $\mathrm{PAO}_{2}$ and is the second cause of a low $\mathrm{PaO}_{2}$ listed in table 2. Because there is no impairment of gas exchange across the alveolar-capillary membrane,

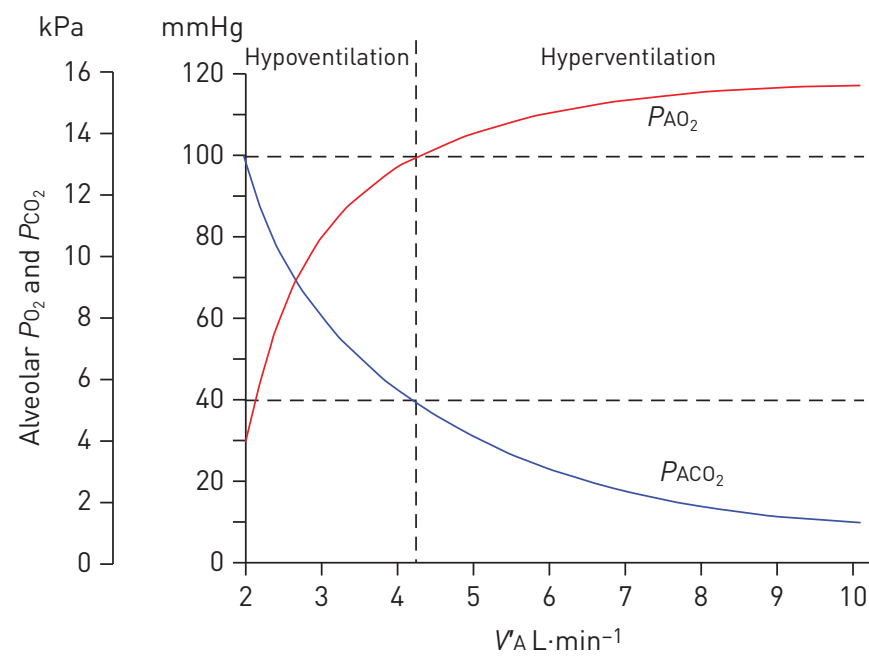

FIGURE 4 The effects of hyper- and hypoventilation on the $P_{\mathrm{AO}_{2}}$ (red) and $\mathrm{PACO}_{2}$ (blue) and, therefore, also on $P \mathrm{aO}{ }_{2}$ and $P_{\mathrm{aCO}}$ if no other $V^{\prime} \mathrm{A} / Q^{\prime}$ mismatch is present. The dashed lines indicate normal values for $V^{\prime} \mathrm{A}, P_{\mathrm{AO}}$ and $P \mathrm{ACO}$. The diagram is derived assuming unchanged cardiac output, $\mathrm{O}_{2}$ consumption and $\mathrm{CO}_{2}$ production with mixed venous values changing with changes in $\mathrm{PaO}_{2}$ and $\mathrm{PaCO}_{2}$. With hypoventilation, $P_{\overline{\mathrm{v}}} \mathrm{O}_{2}$ and $P_{\overline{\mathrm{v}}} \mathrm{CO}_{2}$ are lower and higher than normal, respectively. Note that changes in $V^{\prime}$ A correspond to changes in $V^{\prime} \mathrm{A} / Q^{\prime}$ ratio since blood flow (cardiac output) is held constant. Thus, decreased ventilation (low $V^{\prime} \mathrm{A} / Q^{\prime}$ ratio) causes $P \mathrm{AO}_{2}$ and $P \mathrm{ACO}_{2}$ to move toward the mixed venous values while hyperventilation shifts $\mathrm{PAO}_{2}$ and $\mathrm{PACO}_{2}$ toward their inspired values. Hypoventilation, thus, results in both hypoxaemia and hypercapnia. An increase in $\mathrm{FIO}_{2}$ results in an upward shift of the $\mathrm{PO}_{2}$ curve while the $P \mathrm{CO}_{2}$ curve remains fixed. In this situation, $\mathrm{PaCO}_{2}$ might be high even in the absence of hypoxaemia. For a glossary of terms, see table 1 . Adapted from [10]. 
$\mathrm{PAO}_{2}$ and $\mathrm{PaO}_{2}$ are similarly decreased and the $\mathrm{PA}_{\mathrm{a}-\mathrm{O}}$ is normal in hypoxaemia due to hypoventilation alone. In case 2, the alveolar gas equation (box 1) results in an estimated $P_{A O_{2}}$ of $53 \mathrm{mmHg}(7.1 \mathrm{kPa})$ and $P \mathrm{~A}_{-\mathrm{aO}} \mathrm{O}_{2} \sim 7 \mathrm{mmHg}(0.9 \mathrm{kPa})$, a normal value. Hypoxaemia due to hypoventilation can be resolved with supplemental $\mathrm{O}_{2}$, increasing $\mathrm{PAO}_{2}$ even if hypoventilation remains uncorrected. One important aspect of $\mathrm{O}_{2}$ treatment in this situation is that hypoventilation, while breathing air, will result in severe hypoxaemia before $\mathrm{PaCO}_{2}$ increases to dangerously high levels. In contrast, providing supplemental $\mathrm{O}_{2}$ can result in $\mathrm{PAO}_{2}$ and $\mathrm{PaO}_{2}$ being maintained above $90 \mathrm{mmHg}(12 \mathrm{kPa})$ even with hypoventilation causing severe hypercapnia. A clinically important corollary is that a normal pulse oximetry reading in a patient breathing air is a good indication of adequate ventilation (normal $\mathrm{PaCO}_{2}$ ). However, when a patient is on supplemental $\mathrm{O}_{2}$, a normal $\mathrm{O}_{2}$ saturation cannot be used to judge the adequacy of ventilation.

\section{Low inspiratory oxygen pressure}

In case 3, a 21-year-old very fit, mountaineer notices, while ascending Mont Blanc (4810 $\mathrm{m})$, that her fingers are blue and that her haemoglobin $\mathrm{O}_{2}$ saturation is $65 \%$.

Although the fraction of $\mathrm{O}_{2}$ in air is always 0.21 , decreasing barometric pressure at high altitude causes a proportional decrease in the $\mathrm{PIO}_{2}$. Using the alveolar gas equation (box 1), an appropriate barometric pressure for her altitude $(420 \mathrm{mmHg}(56 \mathrm{kPa}))$, no change in ventilation $\left(\mathrm{PaCO}_{2} 40 \mathrm{mmHg}(5.3 \mathrm{kPa})\right)$ and an $\mathrm{R}$ of 0.8 results in an expected $\mathrm{PAO}_{2}$ at the top of Mont Blanc of $\sim 28 \mathrm{mmHg}(3.7 \mathrm{kPa})$ and severe hypoxaemia. Low $\mathrm{PIO}_{2}$, at high altitude or when breathing an inspiratory $\mathrm{O}_{2}$ fraction $\left(F \mathrm{FO}_{2}\right)<0.21$, is therefore one additional cause of hypoxaemia. Again, gas exchange at the alveolar-capillary membrane is normal. The cause of hypoxaemia is reduced $\mathrm{PAO}_{2}$ and consequently the $\mathrm{PA}_{\mathrm{a}} \mathrm{O}_{2}$ is normal. How is it then possible to ascend Mont Blanc? Hypoxaemia increases the respiratory drive, thereby increasing the total $V^{\prime} \mathrm{A} / Q^{\prime}$ ratio and $\mathrm{O}_{2}$ delivery to the alveoli, which partially corrects $\mathrm{PAO}_{2}$ and $\mathrm{PaO}_{2}$ (fig. 3). Increased ventilation results in hypocapnia, defined as $\mathrm{PaCO}_{2}<40 \mathrm{mmHg}(<5.3 \mathrm{kPa})$. Recent ABG samples from climbers breathing air at the summit of Mount Everest revealed a mean $\mathrm{PaO}_{2}$ of $25 \mathrm{mmHg}(3.3 \mathrm{kPa})$ and $\mathrm{PaCO}_{2}$ of $13 \mathrm{mmHg}(1.7 \mathrm{kPa})$ [11]. A second method to raise $P_{\mathrm{AO}}$ and improve $\mathrm{PaO}_{2}$ is to breathe supplemental $\mathrm{O}_{2}$. Most mountaineers reaching the summit of Mount Everest use supplemental $\mathrm{O}_{2}$.

\section{Two-unit lung models}

For the two remaining causes of hypoxaemia, both examples of $V^{\prime} \mathrm{A} / \mathrm{Q}^{\prime}$ mismatch, we must shift to multiunit lung models. While fascinating in its design and gas exchange capacity, the anatomical structure of the lung with multiple parallel gas exchanging units sets the stage for non-uniform and different distributions of regional ventilation and blood flow. If regional ventilation and perfusion are not perfectly matched, i.e. each unit is not receiving equal proportions of total blood flow and total ventilation, $V^{\prime} \mathrm{A} / Q^{\prime}$ ratios will vary between lung regions, each of them will have different $P_{A O}$ and $P_{A C O}$ and gas exchange will be less efficient. Figure 5 shows the range of $P_{A O}$ and $P_{A C O}$ seen in units as a function of their $V^{\prime} \mathrm{A} / Q^{\prime}$ ratio. To demonstrate how gas exchange becomes less efficient with units of differing $V^{\prime} / Q^{\prime}$ ratios, we will begin with a simple two-unit lung model.

BOX 1 Two versions of the alveolar gas equation

$$
\begin{gathered}
P_{\mathrm{AO}_{2}}=P_{\mathrm{IO}_{2}}-\frac{P_{\mathrm{aCO}_{2}}}{R}=F_{\mathrm{IO}_{2}} \times\left(P_{\mathrm{B}}-P_{\mathrm{H}_{2} \mathrm{O}}\right)-\frac{P_{\mathrm{aCO}_{2}}}{R} \\
P_{\mathrm{AO}_{2}}=P_{\mathrm{IO}_{2}}-\frac{P_{\mathrm{aCO}_{2}}}{R} \times\left[1-F_{\mathrm{IO}_{2}}(1-R)\right]
\end{gathered}
$$

The alveolar equation exists in several forms; the upper version is easier to remember and is used in clinical practice. The lower version is more accurate because it corrects for the difference in inspiratory and expiratory minute volume when the respiratory exchange ratio, $\mathrm{R}$, does not equal 1.0. The equation is used to calculate the alveolar-arterial $\mathrm{O}_{2}$ difference $\left(P \mathrm{~A}-\mathrm{aO} \mathrm{O}_{2}\right)$. In the absence of diffusion limitation, $V^{\prime} \mathrm{A} / \mathrm{Q}^{\prime}$ mismatch and shunt (see text), $\mathrm{PaO}_{2}$ equals $P \mathrm{AO}_{2}$. The $P \mathrm{~A}-\mathrm{aO} \mathrm{O}_{2}$ can, therefore, be used as a measure of the overall deviation from perfect gas exchange.

$\mathrm{PIO}_{2}$ : partial pressure of $\mathrm{O}_{2}$ in inspired gas reaching the alveoli, calculated as $\mathrm{PlO}_{2}=\mathrm{FIO}_{2} \times\left(P \mathrm{~B}-\mathrm{PH}_{2} \mathrm{O}\right)$; FIO $\mathrm{O}_{2}$ : fraction of $\mathrm{O}_{2}$ in inspired gas; $\mathrm{PB}$ : barometric pressure; $\mathrm{PH}_{2} \mathrm{O}$ : saturated vapour pressure of water at body temperature, $47 \mathrm{mmHg}(6.3 \mathrm{kPa})$ at $37^{\circ} \mathrm{C}$; R: the respiratory exchange ratio defined as the ratio between the amount of $\mathrm{CO}_{2}$ and $\mathrm{O}_{2}$ exchange.

PB must be known or estimated for the appropriate altitude; at sea level it is commonly estimated at $760 \mathrm{mmHg}(101.3 \mathrm{kPa})$. If not measured, $\mathrm{R}$ is usually assumed to be 0.8 . Using these values at sea level, the $\mathrm{O}_{2}$ concentration in air $\left(\mathrm{FlO} \mathrm{O}_{2} 0.21\right)$ and a normal $\mathrm{PaCO}_{2}$ of $40 \mathrm{mmHg}(5.3 \mathrm{kPa})$ the upper equation results in $\mathrm{PAO}_{2}$ of $100 \mathrm{mmHg}(13.3 \mathrm{kPa})$. 


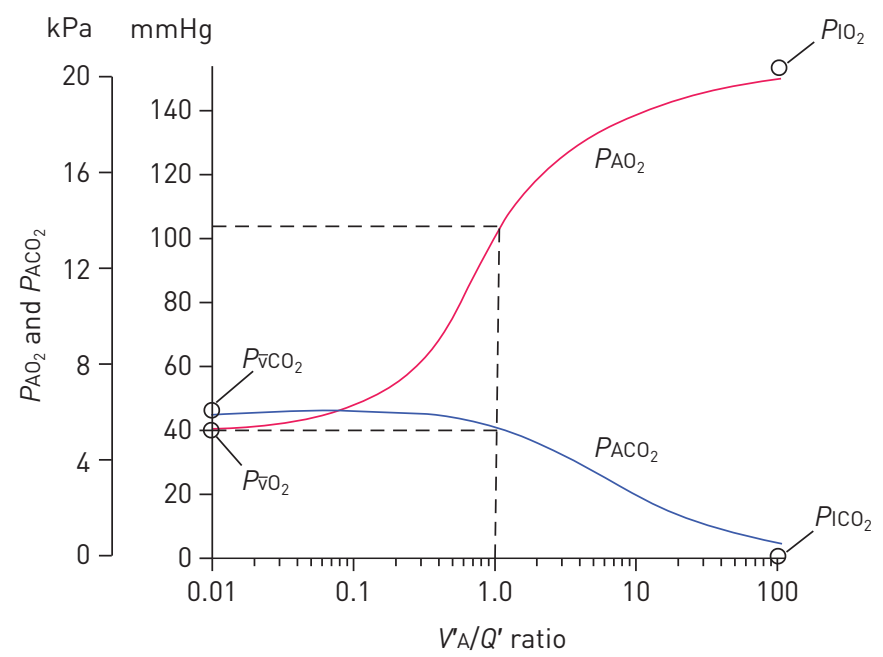

FIGURE 5 Diagram showing how $\mathrm{PAO}_{2}$ and $\mathrm{PACO}_{2}$ vary with the $V^{\prime} \mathrm{A} / Q^{\prime}$ ratio under the assumption of normal values for $P_{\mathrm{IO}_{2}}(150 \mathrm{mmHg}(20 \mathrm{kPa})), P_{\overline{\mathrm{v}}} \mathrm{O}_{2}(40 \mathrm{mmHg}(5.3 \mathrm{kPa}))$ and $P_{\overline{\mathrm{v}} \mathrm{CO}_{2}}(45 \mathrm{mmHg}(6 \mathrm{kPa}))$. These assumptions are not realistic for a whole lung since changes in $\mathrm{PaO}_{2}$ and $\mathrm{PaCO}_{2}$ will cause secondary changes in mixed venous values (fig. 4 is more realistic in this regard), but the diagram illustrates the influence of the $V^{\prime} \mathrm{A} / \mathrm{Q}^{\prime}$ ratio on alveolar and end-capillary partial pressures for regional lung units in a situation when total ventilation to blood flow is sufficient to maintain normal mixed venous values. Note that a decreased $V^{\prime} \mathrm{A} / Q^{\prime}$ ratio below the normal value of $\sim 1$ results in a sharp fall in $P_{\mathrm{AO}_{2}}$ and a lesser increase in $\mathrm{PACO}_{2}$, with both approaching the mixed venous values shown farthest to the left. An increased $V^{\prime} \mathrm{A} / Q^{\prime}$ ratio causes $P_{A} O_{2}$ to increase and $P_{A C O}$ to decrease, approaching the inspired values shown farthest to the right. For a glossary of terms, see table 1 . Adapted from [10].

\section{Low $V^{\prime} A / Q^{\prime}$ units}

In case 4, a 67-year-old female with severe emphysema has an ABG of pH 7.35, $\mathrm{PaO}_{2} 55 \mathrm{mmHg}(7.3 \mathrm{kPa})$ and $\mathrm{PaCO}_{2} 55 \mathrm{mmHg}(7.3 \mathrm{kPa})$ when breathing air. With supplemental $\mathrm{O}_{2}$ at $3 \mathrm{~L} \cdot \mathrm{min}^{-1}$, haemoglobin $\mathrm{O}_{2}$ saturation improves from $87 \%$ to $93 \%$ on pulse oximetry.

Figure 6 illustrates uniform distribution of blood flow but uneven distribution of ventilation to two units, such that one unit has a $V^{\prime} \mathrm{A} / \mathrm{Q}^{\prime}$ ratio of 2.0 while the other unit has a ratio of 0.1 . The low $V^{\prime} \mathrm{A} / Q^{\prime}$ ratio results in low $\mathrm{PAO}_{2}$ in this unit and, thus, lower $\mathrm{O}_{2}$ content and $\mathrm{PecO}_{2}$ for blood leaving this unit. Note that the effect is analogous to that in the patient who was hypoventilating in case 2, but in this case it relates to only a part of the lung. The nearly complete oxygenation of haemoglobin at a normal $V^{\prime} \mathrm{A} / Q^{\prime}$ ratio means that the relative over-ventilation (high $V^{\prime} \mathrm{A} / Q^{\prime}$ ratio) of the other unit results in only a slightly increased $\mathrm{O}_{2}$ content for blood leaving this unit. Also remember that the $\mathrm{O}_{2}$ content of arterial blood $\left(\mathrm{CaO}_{2}\right)$ is determined by the flow-weighted mean of the $\mathrm{O}_{2}$ contents, not partial pressures, for blood from different units. The overall effect of low $V^{\prime} \mathrm{A} / Q^{\prime}$ units is, therefore, a reduced $\mathrm{PaO}_{2}$ and an increased $P \mathrm{~A}-\mathrm{aO} \mathrm{O}_{2}$. Low $V^{\prime} \mathrm{A} / Q^{\prime}$ units are, thus, the fourth cause of hypoxaemia (table 2). The effect of low $V^{\prime} \mathrm{A} / Q^{\prime}$ units on $P_{\mathrm{aCO}}$ is less compared with the effect on $\mathrm{PaO}_{2}$, because $\mathrm{CO}_{2}$ elimination is increased in the unit with a high $V^{\prime} \mathrm{A} / Q^{\prime}$ ratio. In patients with low $V^{\prime} \mathrm{A} / Q^{\prime}$ regions, hypercapnia is also prevented by the ventilatory response to increased $\mathrm{PaCO}_{2}$. Because low $V^{\prime} \mathrm{A} / Q^{\prime}$ regions are in fact ventilated, the detrimental effect on arterial oxygenation can be counteracted by increasing the $\mathrm{FIO}_{2}$, which increases $P \mathrm{AO}_{2}$, even in low $V^{\prime} \mathrm{A} / Q^{\prime}$ regions. Low $V^{\prime} \mathrm{A} / Q^{\prime}$ units, therefore, cannot be the sole cause of hypoxaemia in patients that fail to respond to increased $\mathrm{FIO}_{2}$.

\section{Shunt}

In case 5, a 32-year-old male with severe acute respiratory distress syndrome (ARDS) secondary to bacterial pneumonia has an ABG on mechanical ventilation with an $\mathrm{FIO}_{2}$ of 0.80 that reveals $\mathrm{pH} 7.28, \mathrm{PaO}_{2} 67 \mathrm{mmHg}$ $(8.9 \mathrm{kPa})$ and $\mathrm{PaCO}_{2} 61 \mathrm{mmHg}(8.1 \mathrm{kPa})$.

Figure 7 shows a situation in which one unit is without any ventilation, hence it cannot participate in gas exchange. Blood flow through this unit, therefore, constitutes an intrapulmonary shunt. Shunt can be viewed as one extreme of the range of $V^{\prime} \mathrm{A} / Q^{\prime}$ ratios with a ratio of 0 . End-capillary blood flow from this unit has the same $\mathrm{PecO}_{2}$ and $\mathrm{CecO}_{2}$ as mixed venous blood and when combined with blood from the other unit decreases oxygenation of arterial blood. Shunt is, therefore, the fifth and last cause of hypoxaemia (table 2). The $\mathrm{CaO}_{2}$ is again the flow-weighted average of $\mathrm{O}_{2}$ content from the gas exchanging unit $\left(\mathrm{CecO}_{2}\right)$ and the shunted blood $\left(\mathrm{Cec}^{\prime} \mathrm{O}_{2}\right)$ (fig. 7). The amount of shunt is quantified as the fraction of cardiac output $\left(Q^{\prime} s / Q^{\prime} t\right)$ distributed to nonventilated units (box 2). The effect on arterial oxygenation depends on this 


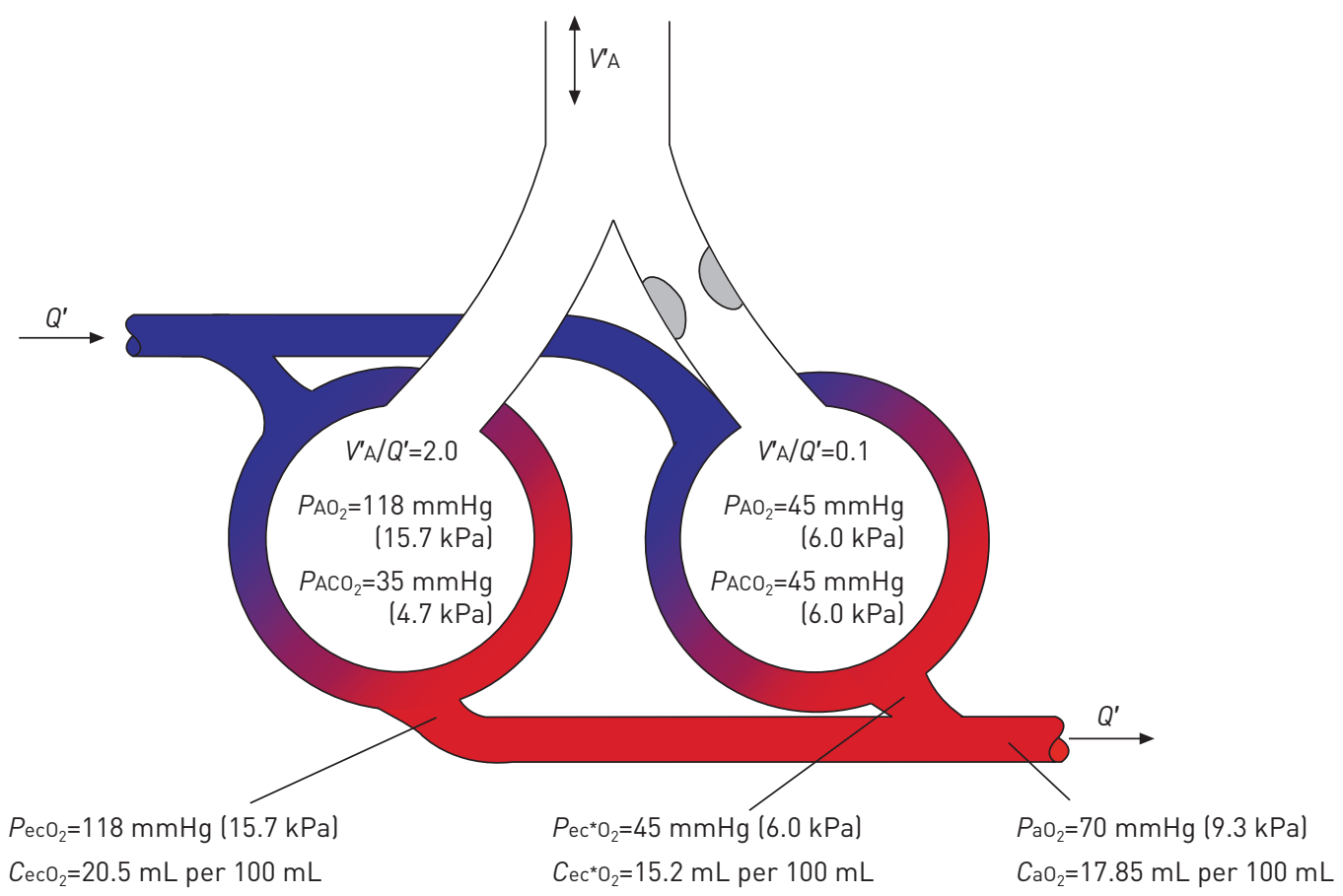

FIGURE 6 Low $V^{\prime} \mathrm{A} / Q^{\prime}$ represented by a two-unit model in which blood flow is the same to both units but ventilation is different, resulting in units with $V^{\prime} \mathrm{A} / Q^{\prime}$ ratios of 2.0 and 0.1 . Note that different $V^{\prime} \mathrm{A} / Q^{\prime}$ ratios result in $P \mathrm{AO}_{2}$ and $P \mathrm{ACO}_{2}$ being very different between the two units. The $\mathrm{CaO}_{2}$ is a flow-weighted average from the two units, in this case identical to the arithmetic means because flow is equal between the units. The $\mathrm{PaO}_{2}$ is determined from the normal haemoglobin $\mathrm{O}_{2}$ saturation versus $\mathrm{PO}_{2}$ curve assuming a haemoglobin concentration of $15 \mathrm{~g} \cdot \mathrm{dL}^{-1}$ (fig. 1b). For a glossary of terms, see table 1, ec and ec $^{\star}$ denotes end-capillary blood from the two different units.

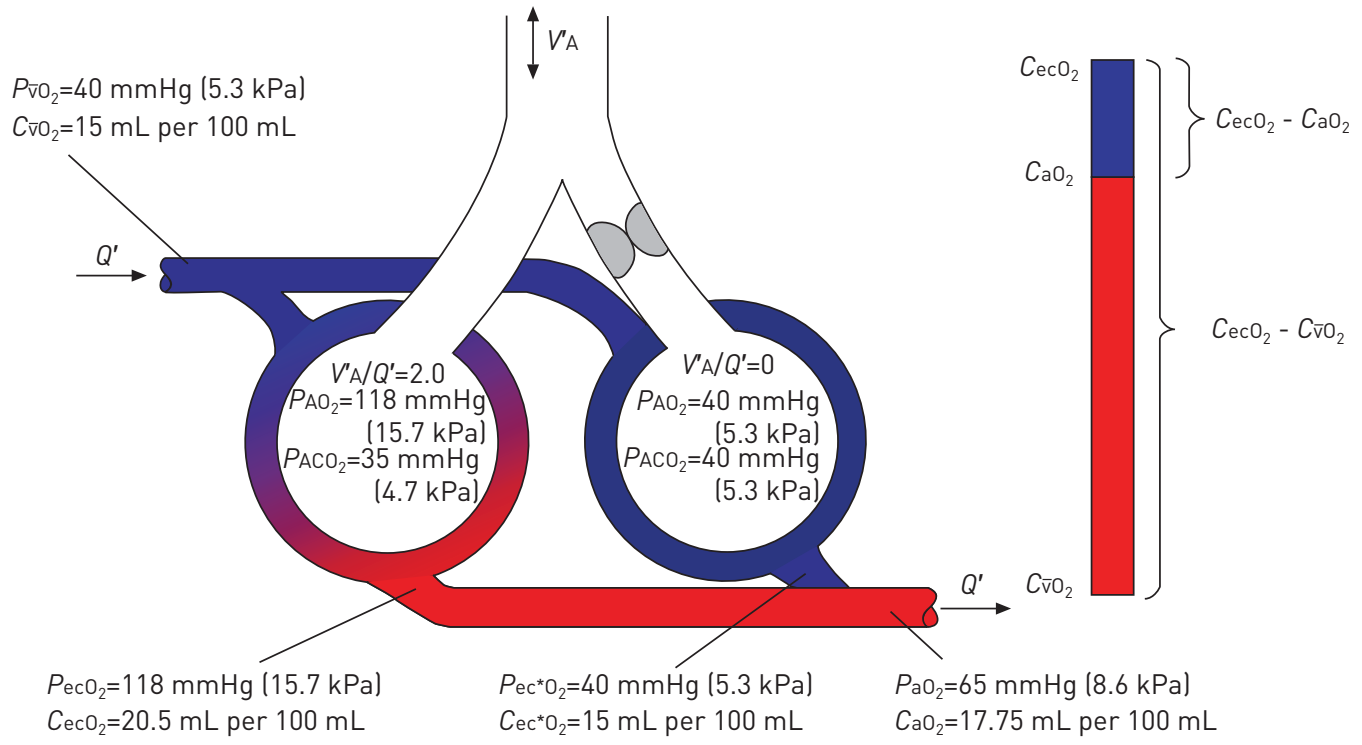

FIGURE 7 Shunt represented by a two-unit model in which blood flow is the same to both units but there is no ventilation to one unit. Note that alveolar and end-capillary $\mathrm{PO}_{2}$ and $\mathrm{PCO}_{2}$ in the nonventilated unit equal the mixed venous values because there is no gas exchange in this unit. The $\mathrm{CaO}_{2}$ is a flow-weighted average of $\mathrm{CecO}_{2}$ and $\mathrm{Cec}^{\star} \mathrm{O}_{2}$ from the two units, or the arithmetic mean when flow is equal between the units as in this example. The $\mathrm{PaO}_{2}$ is determined from the normal haemoglobin $\mathrm{O}_{2}$ saturation versus $\mathrm{PO}_{2}$ curve assuming a haemoglobin concentration of $15 \mathrm{~g} \cdot \mathrm{dL}^{-1}$ (fig. 1b). The vertical bar to the right is a visual representation of the shunt equation (see box 2 and the later section on venous admixture). For a glossary of terms, see table $1, \mathrm{ec}$ and $\mathrm{ec}^{\star}$ denotes end-capillary blood from the two different units. 
BOX 2 The shunt equation

$$
\frac{\mathrm{Q}^{\prime} \mathrm{s}}{\mathrm{Q}^{\prime} \mathrm{t}}=\frac{\mathrm{CecO}_{2}-\mathrm{CaO}_{2}}{\mathrm{CecO}_{2}-\mathrm{C}_{\overline{\mathrm{v}} \mathrm{O}_{2}}}
$$

The shunt equation quantifies the amount of blood in the three-compartment model that reaches the left heart without exchanging any gases. The equation quantitates venous admixture as a fraction of total lung blood flow, i.e. cardiac output. Breathing an $\mathrm{FIO}_{2}$ of 1.0 can be used to eliminate the impact of low $V^{\prime} \mathrm{A} / \mathrm{Q}^{\prime}$ units and, thus, calculate the true shunt. The equation is derived from principles of mass conservation, see for example [12] and figure 7. Notations are explained in table 1. $\mathrm{CaO}_{2}$ and $\mathrm{C}_{\overline{\mathrm{v}}} \mathrm{O}_{2}$ are obtained from samples of arterial and mixed venous blood, respectively; the latter requires a pulmonary artery catheter. $\mathrm{CecO}_{2}$ is calculated assuming that $\mathrm{PecO}_{2}$ equals that of ideal alveolar gas according to the alveolar gas equation. This equation can be conceptualised and graphically presented as shown in the vertical bar of figure $7 . \mathrm{CecO}_{2}$ at the top of the bar is the best the $\mathrm{CaO}_{2}$ could be if there is no shunt at all. $\mathrm{C}_{\mathrm{v}} \mathrm{O}_{2}$ at the bottom of the bar is the worst the $\mathrm{CaO}_{2}$ could be if all of the blood flow was through a shunt. The resultant $\mathrm{CaO}_{2}$ is somewhere between the $\mathrm{C}_{\bar{v}} \mathrm{O}_{2}$ and the $\mathrm{CecO}_{2}$. The fraction of blood flow through the shunt $\left(Q^{\prime} s / Q^{\prime} t\right)$ is, therefore, the observed difference between the $\mathrm{CecO}_{2}$ and $\mathrm{CaO}_{2}$ divided by the potential greatest difference between $\mathrm{CecO}_{2}$ and $\mathrm{C} \overline{\mathrm{V}}_{2}$.

fraction and the $\mathrm{O}_{2}$ content of mixed venous blood $\left(\mathrm{C}_{\overline{\mathrm{v}}} \mathrm{O}_{2}\right)$. For a shunt of a certain magnitude, lower $C_{\overline{\mathrm{v}}} \mathrm{O}_{2}$ will result in worse arterial oxygenation. Interventions aimed at increasing mixed venous $\mathrm{O}_{2}$ saturation $\left(S_{\overline{\mathrm{V}}} \mathrm{O}_{2}\right.$ ) (and consequently $\mathrm{C}_{\overline{\mathrm{V}}} \mathrm{O}_{2}$ ), such as raising the $\mathrm{CaO}_{2}$ through increased haemoglobin concentration, decreasing $\mathrm{O}_{2}$ consumption or increasing cardiac output, might therefore improve hypoxaemia caused by a large shunt. The shunt fraction has, however, been shown to increase with increasing cardiac output $[13,14]$; such interventions might therefore be less effective than expected. Increased $P_{\overline{\mathrm{v}}} \mathrm{O}_{2}$ and increased pulmonary arterial pressure, which may decrease and counteract hypoxic vasoconstriction (discussed later), are speculative explanations for this effect of cardiac output on shunt.

In contrast to the situation with low $V^{\prime} \mathrm{A} / Q^{\prime}$ regions, with shunt increasing $\mathrm{FIO}_{2}$ is much less effective at improving arterial oxygenation. With increasing shunt fraction, the effect of raising $\mathrm{FIO}_{2}$ is progressively less and for very large shunts, even an $\mathrm{FIO}_{2}$ of 1.0 has little effect on $\mathrm{PaO}_{2}$. The reasons for the small effect are that raised $\mathrm{FIO}_{2}$ fails to improve $\mathrm{PAO}_{2}$ in unventilated units and that the little extra $\mathrm{O}_{2}$ that can be added to blood flow through ventilated units is not enough to offset the impact of the shunted blood. The relationships between the variables shunt size, $\mathrm{FIO}_{2}$ and $\mathrm{PaO}_{2}$ are illustrated by the iso-shunt diagram (fig. 8). Examples of clinical conditions with hypoxaemia due to large intrapulmonary shunts are extensive atelectasis, severe pneumonia and ARDS. In these conditions, the shunt might exceed 50\% of total lung blood flow [13, 16-19]. An intracardiac right-to-left shunt has the same effect on $\mathrm{PaO}_{2}$ as an intrapulmonary shunt. Even in normal

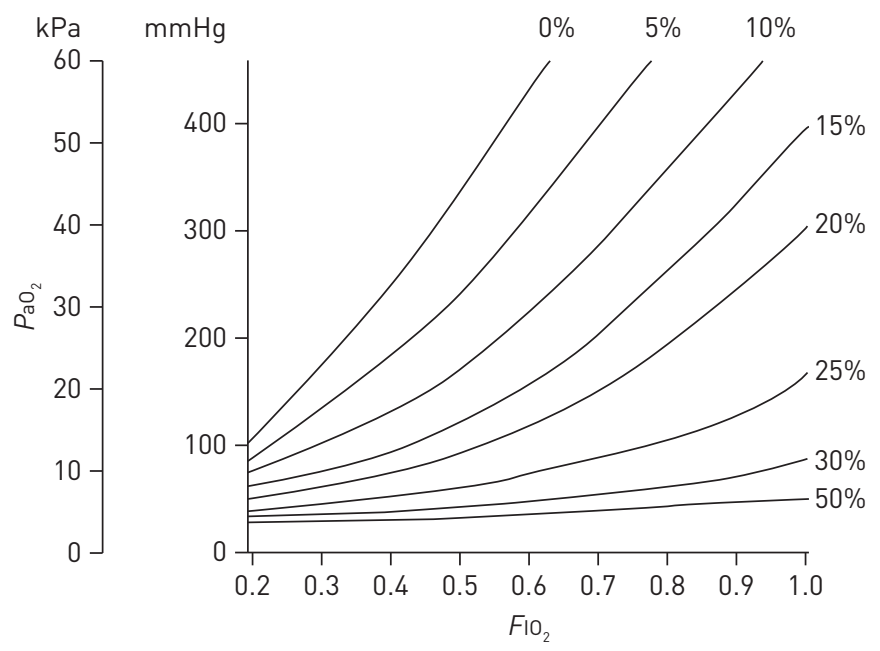

FIGURE 8 The iso-shunt diagram, illustrating the relationship between $\mathrm{PaO}_{2}$ and $F \mathrm{IO}_{2}$ in the presence of a shunt corresponding to different percentages of total lung blood flow. Note the near linear relationship between $\mathrm{PaO}_{2}$ and $F \mathrm{IO}_{2}$ in the absence of shunt. With increasing shunt fractions, the change in $\mathrm{PaO}_{2}$ with increasing $\mathrm{FIO}_{2}$ is much more flat. Hence, a large increase in $\mathrm{FIO}_{2}$ results in little change in $\mathrm{PaO}_{2}$. For a shunt $>30 \%$ of cardiac output, even a FIO ${ }_{2}$ of 1.0 fails to result in a $\mathrm{PaO}_{2}$ of $100 \mathrm{mmHg}(13.3 \mathrm{kPa})$. Modelling is based on a haemoglobin concentration of $14 \mathrm{~g} \cdot \mathrm{dL}^{-1}, \mathrm{PaCO}_{2}$ of $40 \mathrm{mmHg}(5.3 \mathrm{kPa})$ and an arterial-mixed venous oxygen content difference $\left(\mathrm{Ca}-\overline{\mathrm{v}} \mathrm{O}_{2}\right)$ of $5 \mathrm{~mL} \cdot \mathrm{dL}^{-1}$. For a glossary of terms, see table 1. Adapted from [15]. 
BOX 3 Physiological dead space (Bohr) equation

$$
\frac{V_{\mathrm{D}}}{V_{\mathrm{T}}}=\frac{\mathrm{PaCO}_{2}-P_{\overline{\mathrm{E} C O}}}{\mathrm{PaCO}_{2}}
$$

$V_{D}$ is the physiological dead space or wasted ventilation in the three-compartment model. The equation is derived from mass balance calculations that use the alveolar partial pressure of carbon dioxide $\left(\mathrm{PACO}_{2}\right)$, which is here replaced with $\mathrm{PaCO} \mathrm{C}_{2}[20]$. On exhalation, the $\mathrm{PACO}_{2}$ from well perfused lung regions is diluted by the lack of $\mathrm{CO}_{2}$ from the units of dead space. The degree to which the $P \mathrm{ECO}_{2}$ is reduced below the $\mathrm{PaCO}_{2}$ is, thus, proportional to the amount of dead space. This concept is embodied in the vertical bar of figure 9, where the $\mathrm{PaCO}_{2}$ is at the top of the bar and represents the $P \overline{\mathrm{E}} \mathrm{CO}_{2}$ if there is no dead space at all. The $P I C O_{2}$ at the bottom of the bar represents the $P \mathrm{EECO}_{2}$ if the entire lung were dead space. The resultant $P \bar{E} \mathrm{CO}_{2}$ is between these two values. The fraction of wasted ventilation $(\mathrm{VD} / \mathrm{VT})$ is, therefore, the observed difference between $\mathrm{PaCO}_{2}$ and $P \bar{E} \mathrm{CO}_{2}$ divided by the potential greatest difference between $\mathrm{PaCO}_{2}$ and $\mathrm{PICO}_{2}$. Because $\mathrm{PICO}_{2}$ is zero, the denominator reduces to $P a \mathrm{CO}_{2}$ alone. For a glossary of terms, see table 1.

subjects, $\mathrm{PaO}_{2}$ is less than $\mathrm{PAO}_{2}$ due primarily to a right-to-left shunt of $2-3 \%$ of cardiac output. Most of this is not a strict intrapulmonary shunt but represents venous blood added to arterial blood from bronchial veins and the Thebesian veins of the left ventricle [12]. The effect of shunt on $\mathrm{CO}_{2}$ exchange is discussed in box 3 .

\section{Dead space}

In a continuation of case 4, the 67-year-old female with severe emphysema is hospitalised with an acute exacerbation of chronic obstructive pulmonary disease (COPD). ABG reveals $\mathrm{pH} 7.21, \mathrm{PaO}_{2} 67 \mathrm{mmHg}$ $(8.9 \mathrm{kPa})$ and $\mathrm{PaCO}_{2} 85 \mathrm{mmHg}(11.3 \mathrm{kPa})$. Measurements reveal she is breathing $12 \mathrm{~L} \cdot \mathrm{min}^{-1}$.

Despite a minute ventilation $\left(V^{\prime} \mathrm{E}\right)$ that is about twice what is normal at rest, this patient presents with an elevated $\mathrm{PaCO}_{2}$, indicating hypoventilation. How can this be explained? With each inspiration, in all subjects, part of the tidal volume $(V T)$ is retained in the conducting airways and, therefore, fails to contribute to gas exchange. This volume corresponds to the anatomical dead space, and is $\sim 150 \mathrm{~mL}$ $\left(2-3 \mathrm{~mL} \cdot \mathrm{kg}^{-1}\right)$ or one third of a normal $V \mathrm{~T}[12,21]$. A normal dead space fraction of the tidal volume $\left(V \mathrm{D} / V_{\mathrm{T}}\right)$ is therefore $\sim 0.3$. Figure 9 illustrates two units that are equally ventilated but one of the units is without blood

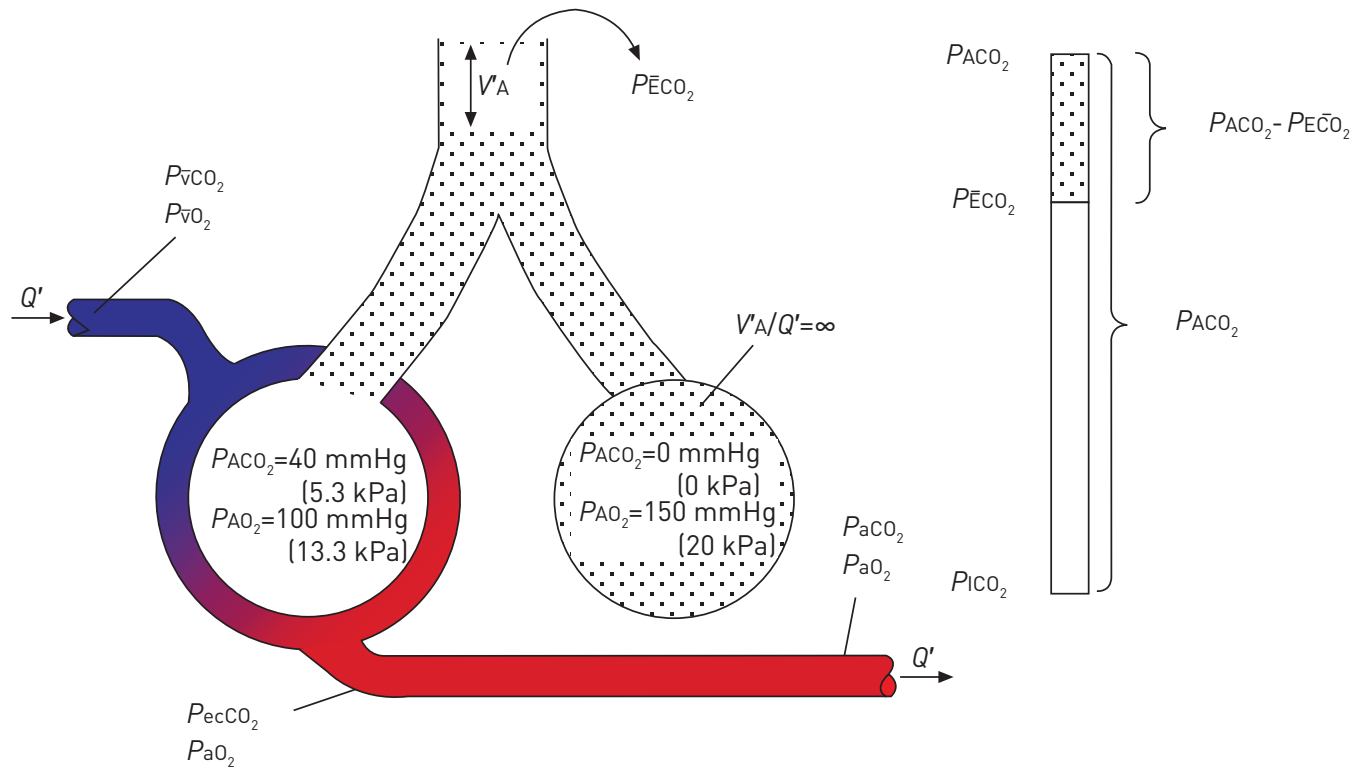

FIGURE 9 Alveolar dead space illustrated by a two-unit model in which there is blood flow to only one unit while there is ventilation to both units. Because no gas exchange occurs in the unit without blood flow, $\mathrm{PAO}_{2}$ and $P_{\mathrm{ACO}}$ in this unit equal the inspired pressures. The dead space unit does not affect arterial blood gases because there is no blood flow contribution from this unit. The lack of $\mathrm{CO}_{2}$ expired from the dead space region dilutes the concentration of $\mathrm{CO}_{2}$ expired from the other unit and expired $\mathrm{PCO}_{2}$ is thus lower than from perfused units. The degree by which the expired $P \mathrm{CO}_{2}$ is decreased in comparison with $\mathrm{PaCO}_{2}$ is proportional to the fraction of the lung that is dead space. The vertical bar to the right is a visual representation of the dead space equation (box 3). It is analogous to that in figure 7 and explained in the section on wasted ventilation. For a glossary of terms, see table 1. 


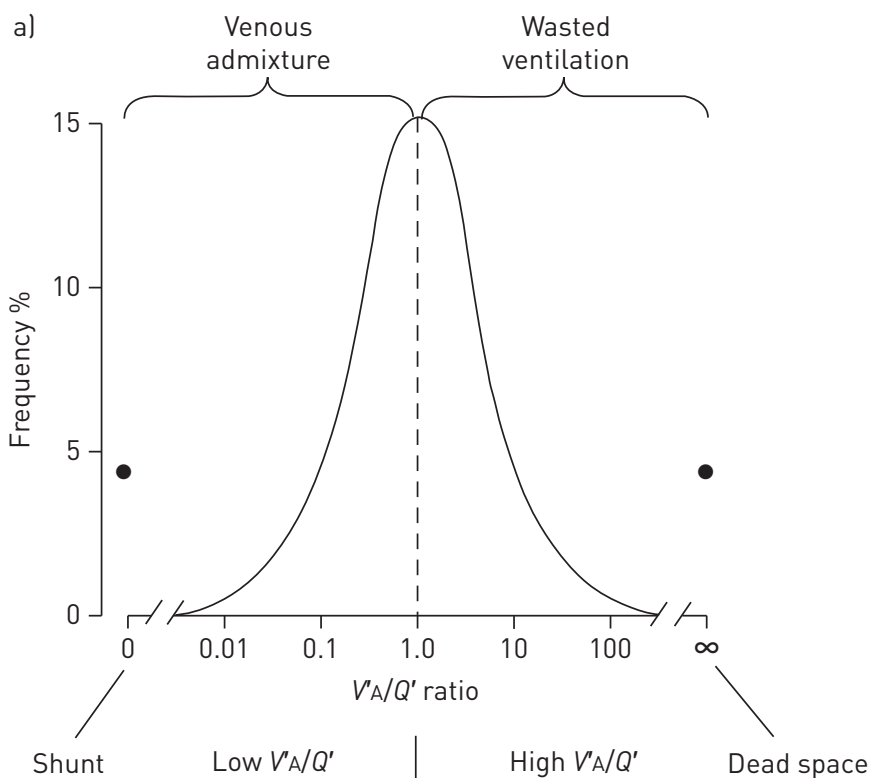

b)

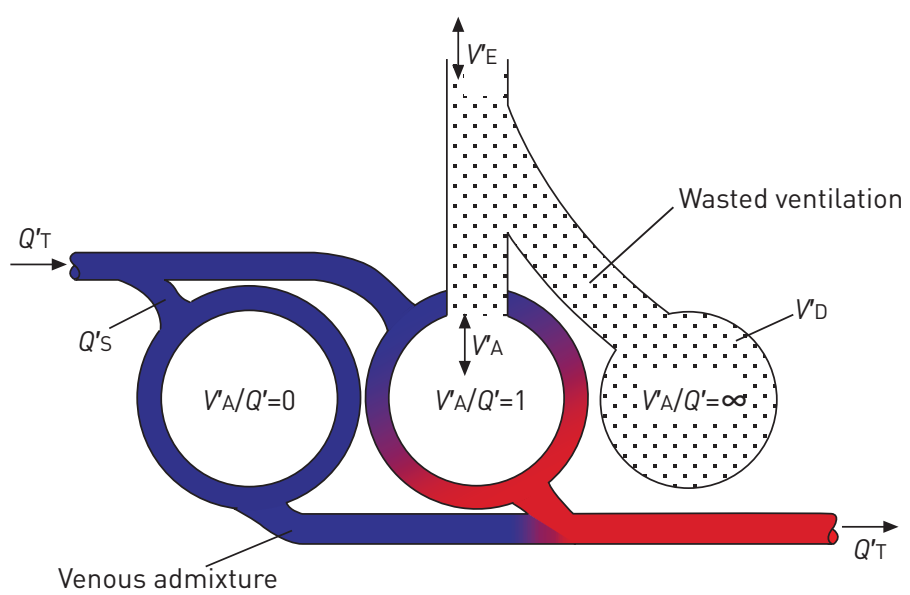

FIGURE 10 a) Percentage of lung units (vertical axis) with different $V^{\prime} \mathrm{A} / \mathrm{Q}^{\prime}$ ratios (horizontal axis) in a lung that has an overall $V^{\prime} \mathrm{A} / \mathrm{Q}^{\prime}$ of 1.0 (minute ventilation is the same as cardiac output). Overall gas exchange efficiency is determined by the spread of units across different ratios, with optimal efficiency corresponding to a very narrow distribution with all units having a ratio of 1.0. The curve illustrates the normal situation with most units having a ratio close to optimal. Units to the left of the dashed line have a low ratio and, therefore, contribute to increased $\mathrm{PA}-\mathrm{aO}_{2}$ and venous admixture; the effect increases with increasing deviation from a ratio of 1.0. Units to the right of the dashed line have a high ratio and, therefore, contribute to wasted ventilation; again the effect increases with increasing deviation from a ratio of 1.0. Shunt and dead space units are plotted at the two extremes of the horizontal axis. b) Illustration of the three-compartment model proposed by RILEY and Cournand [9] to quantify $V^{\prime} \mathrm{A} / \mathrm{Q}^{\prime}$ mismatch as venous admixture and wasted ventilation. For a glossary of terms, see table 1.

flow and, therefore, constitutes alveolar dead space. One clinical cause might be pulmonary embolism. Alveolar dead space refers to gas exchanging units that are ventilated but without blood flow and the $V^{\prime} \mathrm{A} / Q^{\prime}$ ratio is infinite. Apparatus dead space refers to the volume of any face mask, tubing, etc. that functions as an extension of the anatomical dead space. Total dead space (VD), therefore, consists of summed anatomical dead space, alveolar dead space and any apparatus dead space.

Minute ventilation refers to the total volume of expired gas per minute, while effective alveolar ventilation refers to the volume of gas per minute that participates in gas exchange. In contrast, dead space ventilation, or wasted ventilation, is the fraction of total ventilation that does not contribute to gas exchange. This fraction of wasted ventilation is often expressed as the ratio $V \mathrm{D} / V \mathrm{~T}$. Effective alveolar ventilation can be calculated as $V^{\prime} \mathrm{A}=\mathrm{RR} \times(V \mathrm{~T}-V \mathrm{D})$, where $\mathrm{RR}$ is respiratory rate, or as $V^{\prime} \mathrm{A}=V^{\prime} \mathrm{E} \times\left(1-V_{\mathrm{D}} / V_{\mathrm{T}}\right)$. Note that effective alveolar ventilation is determined by both minute ventilation and $V \mathrm{D} / V \mathrm{~T}$. Increased $V \mathrm{D}$ inherently means that a greater minute ventilation is needed to maintain effective alveolar ventilation adequate for $\mathrm{CO}_{2}$ removal. An increase in $V \mathrm{D} / V \mathrm{~T}$ without a compensatory increase in minute ventilation results in decreased $\mathrm{PaO}_{2}$ and increased $\mathrm{PaCO}_{2}$. In the patient in case 4, the high minute ventilation is not enough to compensate for the increased $V \mathrm{D} / V \mathrm{~T}$, which results in hypercapnia. Increased $\mathrm{PaCO}_{2}$ might also be seen in those sedated and mechanically ventilated patients who do not increase their minute ventilation in the setting of a new pulmonary embolism.

High $V^{\prime} A / Q^{\prime}$ units

High $V^{\prime} \mathrm{A} / Q^{\prime}$ units are units that are overventilated in proportion to blood flow, for example, a unit that receives a ventilation of $1 \mathrm{~L} \cdot \mathrm{min}^{-1}$ but a blood flow of only $0.1 \mathrm{~L} \cdot \mathrm{min}^{-1}$ resulting in a $V^{\prime} \mathrm{A} / \mathrm{Q}^{\prime}$ ratio of 10 . Although this unit does not represent alveolar dead space, ventilation in excess of blood flow causes a "dead space effect", because less $\mathrm{CO}_{2}$ will be removed by ventilation of a high $V^{\prime} \mathrm{A} / Q^{\prime}$ unit than by ventilation of a better perfused region. Thus, similar to alveolar dead space, addition of high $V^{\prime} \mathrm{A} / Q^{\prime}$ units means that a greater minute ventilation is needed to maintain adequate gas exchange. High $V^{\prime} \mathrm{A} / \mathrm{Q}^{\prime}$ regions are primarily due to areas of normal ventilation with low blood flow. The impact of these regions on ABGs is small, because the contribution of any region to ABG composition is flow-weighted.

\section{More than two-unit lung models}

So far we have focused on models with one or two lung units. In reality, gas exchange within the entire lung and the resulting $\mathrm{PaO}_{2}$ and $\mathrm{PaCO}_{2}$ are determined by the effluent blood flow from thousands of units with 
different $V^{\prime} \mathrm{A} / Q^{\prime}$ ratios (fig. 10). Riley and Cournand [9] suggested that the effect of $V^{\prime} \mathrm{A} / Q^{\prime}$ mismatch on gas exchange can be more simply thought of and quantified as a lung consisting of only three compartments with different $V^{\prime} \mathrm{A} / Q^{\prime}$ ratios: one compartment with ideal $V^{\prime} \mathrm{A} / Q^{\prime}$ matching $\left(V^{\prime} \mathrm{A} / Q^{\prime}=1.0\right)$, one totally without ventilation $\left(V^{\prime} \mathrm{A} / Q^{\prime}=0\right.$, shunt $)$ and one without blood flow $\left(V^{\prime} \mathrm{A} / Q^{\prime}=\infty\right.$, dead space).

The model is practical because it is relatively easy to obtain the measurements needed to quantify shunt blood flow and dead space ventilation (discussed below). It is important to understand that the calculations assume that the effects of $V^{\prime} \mathrm{A} / Q^{\prime}$ mismatch on $\mathrm{PaO}_{2}$ and $\mathrm{PaCO}_{2}$ are entirely due to shunt and dead space ventilation, and that all gas exchange occurs in units with ideal $V^{\prime} \mathrm{A} / Q^{\prime}$ matching. The model does not reflect the true situation as it ignores gas exchange in units with other $V^{\prime} \mathrm{A} / \mathrm{Q}^{\prime}$ ratios.

\section{Venous admixture}

With the three-compartment model, shunt blood flow is calculated using the shunt equation (box 2). The calculated shunt, alternatively and more accurately described as venous admixture, corresponds to the amount of right-to-left shunt of mixed venous blood that would result in the observed arterial oxygenation in the absence of low $V^{\prime} \mathrm{A} / Q^{\prime}$ regions. Venous admixture might, therefore, be increased even in the absence of true shunt.

Using values obtained while breathing $100 \% \mathrm{O}_{2}$ can differentiate hypoxaemia due to low $V^{\prime} \mathrm{A} / \mathrm{Q}^{\prime}$ regions from the effect of a true shunt, because the venous admixture from low $V^{\prime} \mathrm{A} / \mathrm{Q}^{\prime}$ regions is abolished in this situation [12]. One problem with this approach is that breathing $100 \% \mathrm{O}_{2}$ tends to increase the amount of shunt due to absorption atelectasis so the degree of shunt while breathing a lower $\mathrm{FIO}_{2}$ might be overestimated. Shunt can also be measured using inert gases with low solubility in blood [17, 22]. It should be noted that this methodology also differs from the calculation of venous admixture as it excludes the shunt effect of venous blood added to arterial blood after the passage through the lung, from Thebesian and bronchial veins.

\section{Wasted ventilation (physiological dead space)}

According to the three-compartment model of Riley and Cournand [9], physiological dead space or wasted ventilation corresponds to the total dead space that would cause the observed impairment of $\mathrm{CO}_{2}$ elimination (box 3). We prefer the term "wasted ventilation", since it better describes the meaning of this quantity. In normal lungs, the wasted ventilation closely corresponds to the anatomical dead space. In addition to anatomical dead space, wasted ventilation also results from any apparatus, alveolar dead space and high $V^{\prime} \mathrm{A} / Q^{\prime}$ units. Blood from shunt regions will have a $P \mathrm{ecCO}_{2}$ equal to the mixed venous value, which raises $\mathrm{PaCO}_{2}$ and thereby the calculated wasted ventilation; this has been coined shunt dead space [21]. This is an effect of using $\mathrm{PaCO}_{2}$ as a surrogate for $\mathrm{PACO}_{2}$; hence, while not an effect of increased dead space or high $V^{\prime} \mathrm{A} / Q^{\prime}$ regions, it does represent impaired $\mathrm{CO}_{2}$ elimination [23]. As discussed above, effective alveolar ventilation equals minute ventilation minus wasted ventilation. A minute ventilation of $7.5 \mathrm{~L} \cdot \mathrm{min}^{-1}$ and a normal $V \mathrm{D} / V \mathrm{~T}$ of 0.3 results in an effective alveolar ventilation of $5.25 \mathrm{~L} \cdot \mathrm{min}^{-1}$. Chronic lung disease might increase $V \mathrm{D} / V_{\mathrm{T}}$ to $\geqslant 0.8$; in this case, a minute ventilation of $\geqslant 25 \mathrm{~L} \cdot \mathrm{min}^{-1}$ is required for an effective alveolar ventilation of $5 \mathrm{~L} \cdot \mathrm{min}^{-1}$. Measures of wasted ventilation, thus, estimate the effect of $V^{\prime} \mathrm{A} / \mathrm{Q}^{\prime}$ mismatch on the minute ventilation needed to maintain adequate gas exchange. Although not measured, for the patient in case 4, the increased $\mathrm{PaCO}_{2}$ despite a high minute ventilation is most likely explained by a greater component of wasted ventilation.

Because the control of breathing aims to maintain a normal $\mathrm{PaCO}_{2}$, an increase in wasted ventilation requires an increased minute ventilation to maintain unchanged effective alveolar ventilation. The first consequence of increased wasted ventilation in most situations is, therefore, not an increase in $\mathrm{PaCO}_{2}$ but a change in minute ventilation and, therefore, the work of breathing. Chronic hypercapnia can be viewed as an adaptive response as it means that $\mathrm{CO}_{2}$ removal can be maintained with a lower minute ventilation and, thus, lessens the work of breathing.

\section{The arterial to end-tidal $\mathrm{PCO}_{2}$ difference}

The physiological dead space equation (box 3) uses the difference between $\mathrm{PaCO}_{2}$ and the $\mathrm{PCO}_{2}$ of mixed expired gas $\left(P \overline{\mathrm{E}} \mathrm{CO}_{2}\right)$ to calculate the total fraction of wasted ventilation. By contrast, the difference between $\mathrm{PaCO}_{2}$ and the $\mathrm{PCO}_{2}$ of mixed expired alveolar gas excludes the effect of anatomical and apparatus dead space and, therefore, estimates the extent of high $V^{\prime} \mathrm{A} / Q^{\prime}$ and alveolar dead space regions. Because the last part of the exhaled $V \mathrm{~T}$ consists of alveolar gas (box 4), the end-tidal $P_{\mathrm{CO}_{2}}\left(P \mathrm{ETCO}_{2}\right)$ can be used as a surrogate measure of mixed $\mathrm{PACO}_{2}$. The $\mathrm{PaCO}_{2}-\mathrm{EETCO}_{2}$ difference, therefore, correlates with dead space and wasted ventilation [28-30]. It is noteworthy that, remembering the physiological dead space equation, modelling studies have shown that $\left(\mathrm{PaCO}_{2}-\mathrm{PETCO}_{2}\right) / \mathrm{PaCO}_{2}$ has a more linear correlation with alveolar dead space fraction than the simpler $\mathrm{PaCO}_{2}-\mathrm{PETCO}_{2}[29,30]$. Although dependent on, for example, age, the inhaled/ 


\section{BOX 4 End-tidal $\mathrm{PCO}_{2}\left(\mathrm{PETCO}_{2}\right)$}

At expiration, the first part of the exhaled gas originates from the anatomical dead space where no gas exchange occurs. Therefore, this gas has the same $\mathrm{PCO}_{2}$ as inspired gas, usually close to zero (fig. 11). After a short transitional phase consisting of a mixture of anatomical dead space and alveolar gas, the rest of the expiration consists of mixed alveolar gas. Measurement of $\mathrm{PCO}_{2}$ of exhaled gas at the end of the expiration, $\mathrm{PETCO}_{2}$, has been used as a measure of mixed alveolar gas and as a noninvasive measure of $\mathrm{PaCO}_{2}$. There are, however, several considerations with this approach. In diseased lung the proportion of airflow from different lung regions might change during expiration, with different regions emptying sequentially rather than in parallel. In this situation, late emptying of low $V$ 'A/Q' regions with a high $P_{A C O}$ causes the $\mathrm{PCO}_{2}$ to increase throughout expiration and potentially be greater than the mean $\mathrm{PACO}_{2}$ at the end of exhalation [24]. Even with healthy lungs, a similar phenomenon occurs when breathing with large tidal volumes during exercise $[25,26]$. In this case, one important cause is that $P_{A C O_{2}}$ increases during the course of expiration due to more $\mathrm{CO}_{2}$ being added to alveolar gas [27]. In these situations $P \mathrm{ETCO}_{2}$ might in fact even be greater

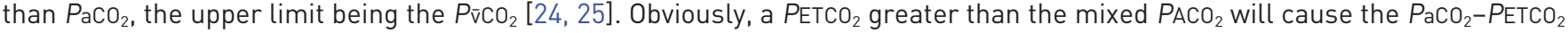
to underestimate wasted ventilation.

exhaled gas volume and mode of ventilation, a $\mathrm{PaCO}_{2}-\mathrm{ETCO}_{2}<5 \mathrm{mmHg}(0.7 \mathrm{kPa})$ is considered normal $[31,32]$ and is supported by $\mathrm{PETCO}_{2}$ being close to $36 \mathrm{mmHg}(4.8 \mathrm{kPa})$ in a small number of normal subjects [33]. $\mathrm{PaCO}_{2}-\mathrm{PETCO}_{2}$ has been shown to correlate with alveolar dead space fraction and alveolar recruitment in animal models of ARDS [34]. $\mathrm{ETCO}_{2}$ is illustrated in figure 11 and further discussed in box 4.

\section{The combined effect of low and high $V^{\prime} A / Q^{\prime}$ regions}

In comparison with optimal $V^{\prime} \mathrm{A} / Q^{\prime}$ matching, redistribution of either regional ventilation or blood flow must result in both low and high $V^{\prime} \mathrm{A} / \mathrm{Q}^{\prime}$ regions. For example, a shift in blood flow from one unit to another will cause one unit to be less perfused in proportion to ventilation (high $V^{\prime} \mathrm{A} / \mathrm{Q}^{\prime}$ ) and the other unit to be more perfused in proportion to ventilation (low $V^{\prime} \mathrm{A} / Q^{\prime}$ ). Compared with the effect on $P_{\mathrm{aCO}}$, the effect of $V^{\prime} \mathrm{A} / Q^{\prime}$ mismatch on $\mathrm{PaO}_{2}$ is often more obvious because 1) the numerical changes in $\mathrm{PaO}_{2}$ are larger than those in $\mathrm{PaCO}_{2}$ and 2) impaired $\mathrm{CO}_{2}$ elimination is often counteracted by increased minute ventilation which offsets the effect of $V^{\prime} \mathrm{A} / \mathrm{Q}^{\prime}$ mismatch on $\mathrm{PaCO}_{2}$ to a much greater degree than the effect on $\mathrm{PaO}_{2}$. The net effect of $V^{\prime} \mathrm{A} / Q^{\prime}$ mismatch is always reduced gas exchange efficiency and for a given $\mathrm{FIO}_{2}$ and minute ventilation results in lower $\mathrm{PaO}_{2}$ and higher $\mathrm{PaCO}_{2}$ than would have occurred if $V^{\prime} \mathrm{A} / Q^{\prime}$ matching were optimal.

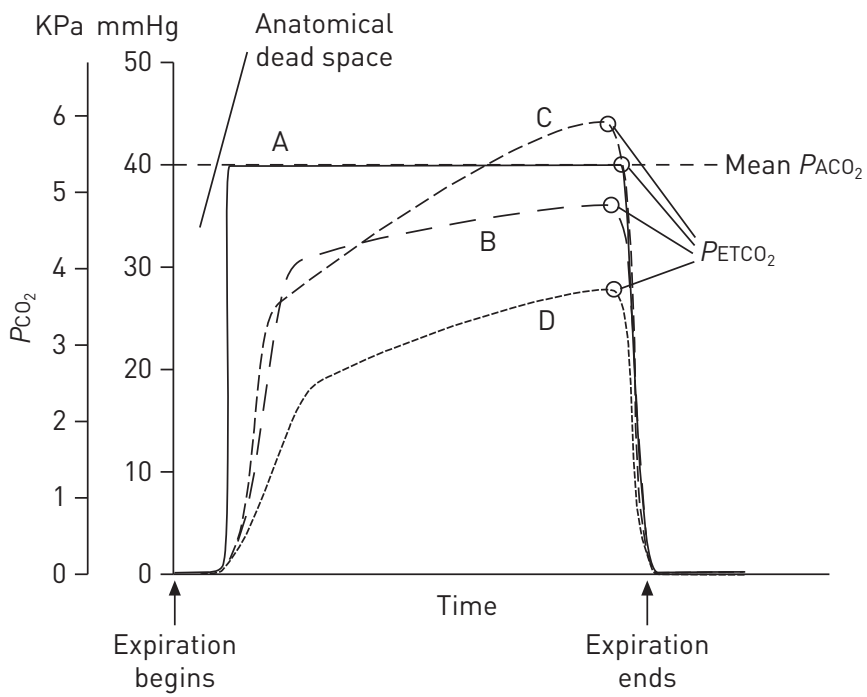

FIGURE 11 Capnogram showing the $\mathrm{PCO}_{2}$ of exhaled gas (vertical axis) plotted versus time (horizontal axis) during a single exhalation. Curve A corresponds to a theoretical curve from a single lung unit model in which the first part of the exhalation consists solely of anatomical dead space gas without $\mathrm{CO}_{2}$ and the rest of the exhaled alveolar gas has a uniform $P_{\mathrm{CO}_{2}}$ that is equal to $P \mathrm{ACO}_{2}$. In this single-unit model, $\mathrm{PETCO}_{2}=\mathrm{PACO}_{2}=\mathrm{PaCO}_{2}$. Curve $\mathrm{B}$ corresponds to a capnogram from a healthy individual with a normal amount of $V^{\prime} \mathrm{A} / \mathrm{Q}^{\prime}$ mismatching. Note that there would be a small difference between the $P \mathrm{ETCO}_{2}$ (marked with an open circle) and $P_{\mathrm{aCO}}$. Curve C illustrates how increased $V^{\prime} \mathrm{A} / Q^{\prime}$ causes the $P \mathrm{CO}_{2}$ of exhaled gas to increase throughout expiration. In this case $P_{\mathrm{ETCO}}$ even exceeds $\mathrm{PACO}_{2}$ and possibly $\mathrm{PaCO}_{2}$. While this is not common, it can occur with slow exhalation of a large $V$ T or at maximal exercise. Curve D illustrates a situation with increased alveolar dead space, resulting in an increased difference between $\mathrm{PaCO}_{2}$ and $\mathrm{PETCO}_{2}$, as might be seen in a patient with a pulmonary embolism. For a glossary of terms, see table 1 . 


\section{$V^{\prime} \mathrm{A} / \mathrm{Q}^{\prime}$ mismatch in the normal lung}

Regional ventilation and blood flow are not uniform in the normal lung. Heterogeneities of ventilation and perfusion have been attributed to the influence of airway and vascular tree geometries as well as regional differences in blood flow and lung compliance due to gravity [35-39]. The traditional zone model [38] of perfusion and ventilation predicts that both perfusion and ventilation increase in the gravitational direction, from apex to lung base in the upright posture. However, they do not increase at the same rate, and $V^{\prime} / Q^{\prime}$ tends to decrease from apex to base. Animal studies using higher spatial resolution measurements have suggested a fractal model [40,41], in which asymmetries in the vascular tree result in perfusion heterogeneities that cannot be explained by the hydrostatic gradient due to gravity. Regional ventilation and blood flow are further influenced by posture, lung volume and application of positive airway pressures $[36,37,42]$, to name just a few factors. Despite these non-uniformities, efficient gas exchange is possible through the close matching of ventilation and blood flow, attributed to the shared influences of structure and gravity [35]. The correlation is, however, not perfect, which causes $V^{\prime} \mathrm{A} / Q^{\prime}$ ratios and, therefore, $P \mathrm{AO}_{2}$ and $\mathrm{PACO}_{2}$, to vary between different lung regions [35].

In young healthy individuals, most ventilation and blood flow are distributed to units with $V^{\prime} \mathrm{A} / \mathrm{Q}^{\prime}$ ratios between 0.3 and 2.0 [22], which tends to result in a range of $\mathrm{PAO}_{2}$ from about $90 \mathrm{mmHg}$ to $130 \mathrm{mmHg}$ (fig. 5) [43]. With increasing age, ventilation and blood flow are distributed to units with a wider range of $V^{\prime} \mathrm{A} / Q^{\prime}$ ratios, with blood flow to low $V^{\prime} \mathrm{A} / \mathrm{Q}^{\prime}$ regions being attributed to reduced ventilation of dependent lung regions due to airway closure $[12,44]$. Consequently, $\mathrm{PA}-\mathrm{aO}_{2}$ increases with age $[12,44]$.

\section{Assessing arterial oxygenation}

Several indices are used to evaluate $\mathrm{PaO}_{2}$ in relation to $\mathrm{FIO}_{2}$. When breathing air, the $\mathrm{PA}-\mathrm{aO} \mathrm{O}_{2}$ provides a sensitive measure of gas exchange efficiency but is dependent on age. A number of different studies have sampled relatively small numbers of individuals in different populations to determine the distribution of $P \mathrm{~A}-\mathrm{aO}_{2}$ in normal individuals [45-48]. In all studies, the mean $\mathrm{PA}-\mathrm{aO}_{2}$ increases with age, as do the confidence intervals around the mean. Table 3 incorporates data from two of the larger populations $[45,46]$. A simplified formula for the normal $\mathrm{PA}-\mathrm{aO}_{2}$ when breathing air is (age in years/4) $+4 \mathrm{mmHg}$ (divide result by 7.5 for $\mathrm{kPa}$ ). Because the normal $\mathrm{PA}-\mathrm{aO} \mathrm{O}_{2}$ is primarily due to venous admixture, increasing $\mathrm{FIO}_{2}$ raises $\mathrm{PAO}_{2}$ more than $\mathrm{PaO}_{2}$ and the normal value for $\mathrm{PA}-\mathrm{aO}_{2}$ increases with increasing $\mathrm{FIO}_{2}$. The $\mathrm{PaO}_{2} / \mathrm{FIO}_{2}$ ratio is more frequently used in clinical practice and in the definition of ARDS. A lower limit for normal $\mathrm{PaO}_{2}$ when breathing air of $80 \mathrm{mmHg}(10.7 \mathrm{kPa})$ corresponds to a normal $\mathrm{PaO}_{2} / \mathrm{FIO}_{2}$ ratio being $>400 \mathrm{mmHg}(53 \mathrm{kPa})$, while diagnosing ARDS requires a $\mathrm{PaO}_{2} / \mathrm{FIO}_{2}<300 \mathrm{mmHg}\left(40 \mathrm{kPa}\right.$ ). The $\mathrm{PaO}_{2} / \mathrm{FIO}_{2}$ is also dependent on the $\mathrm{FIO}_{2}$, level of positive end-expiratory pressure (PEEP) and the arterial venous $\mathrm{O}_{2}$ extraction $[49,50]$ and is, therefore, a difficult measure to interpret. The $\mathrm{PaO}_{2} / \mathrm{FIO}_{2}$ is not helpful in differentiating between different causes of hypoxaemia.

\section{$V^{\prime} \mathrm{A} / \mathrm{Q}^{\prime}$ mismatch and vascular tone}

Hypoxic pulmonary vasoconstriction

Hypoxic pulmonary vasoconstriction (HPV) causes pre-capillary vasoconstriction in units with low $P_{\mathrm{AO}_{2}}$ $(<60 \mathrm{mmHg}(8.0 \mathrm{kPa}))$, such as those with low $V^{\prime} \mathrm{A} / \mathrm{Q}^{\prime}$ or shunt [51-54]. The effect of HPV is to divert blood flow away from hypoxic units toward better ventilated units, improving $V^{\prime} \mathrm{A} / Q^{\prime}$ matching and arterial

\section{TABLE $3 \mathrm{PaO}_{2}$ and $\mathrm{PA}_{-} \mathrm{aO}_{2}$ at different ages}

\begin{tabular}{|c|c|c|c|c|c|c|c|c|}
\hline \multirow[t]{2}{*}{ Age years } & \multicolumn{2}{|c|}{ Mean $\mathrm{PaO}_{2}$} & \multicolumn{2}{|c|}{$\begin{array}{l}\text { Lower 95th percentile } \\
\text { of } \mathrm{PaO}_{2}\end{array}$} & \multicolumn{2}{|c|}{ Mean $\mathrm{PA}-\mathrm{aO}_{2}$} & \multicolumn{2}{|c|}{$\begin{array}{c}\text { Upper } 95 \text { th percentile } \\
\text { of }{\mathrm{PA}-\mathrm{aO}_{2}}\end{array}$} \\
\hline & $\mathrm{mmHg}$ & $\mathrm{kPa}$ & $\mathrm{mmHg}$ & $\mathrm{kPa}$ & $\mathrm{mmHg}$ & $\mathrm{kPa}$ & $\mathrm{mmHg}$ & $\mathrm{kPa}$ \\
\hline $18-24$ & 99.9 & 13.3 & 91.1 & 12.1 & 2.0 & 0.3 & 11.4 & 1.5 \\
\hline $25-34$ & 99.8 & 13.3 & 91.7 & 12.2 & 3.3 & 0.4 & 7.4 & 1.0 \\
\hline $35-44$ & 98.3 & 13.1 & 85.8 & 11.4 & 4.7 & 0.6 & 17.1 & 2.3 \\
\hline $45-54$ & 97.0 & 12.9 & 83.8 & 11.2 & 6.5 & 0.9 & 17.1 & 2.3 \\
\hline $55-64$ & 90.2 & 12.0 & 82.8 & 11.0 & 12.1 & 1.6 & 18.2 & 2.4 \\
\hline$>64$ & 88.7 & 11.8 & 71.1 & 9.5 & 14.8 & 2.0 & 29.3 & 3.9 \\
\hline Males >70 & 77.0 & 10.3 & 62.0 & 8.3 & 25.2 & 3.4 & 40.4 & 5.4 \\
\hline Females >70 & 73.5 & 9.8 & 59.6 & 7.9 & 28.1 & 3.7 & 41.3 & 5.5 \\
\hline
\end{tabular}

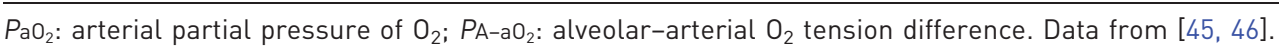




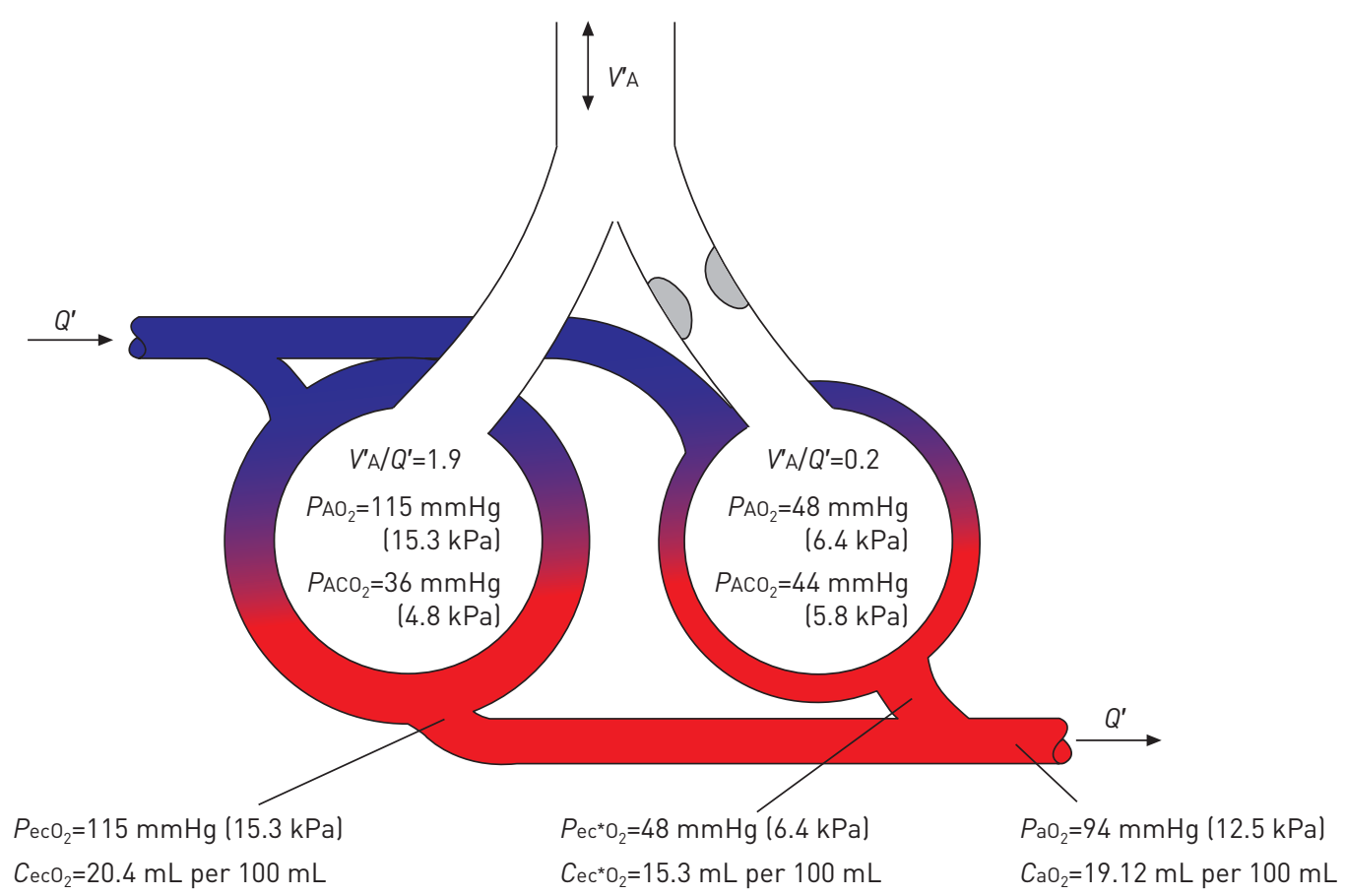

FIGURE 12 Hypoxic pulmonary vasoconstriction (HPV) occurs in lung regions with low $\mathrm{PAO}_{2}$, effectively redistributing blood flow away from the hypoxic regions and towards better oxygenated regions. The distribution of ventilation is identical to that in figure 6 but blood flow to the low $V^{\prime} \mathrm{A} / \mathrm{Q}^{\prime}$ unit is halved due to HPV. Compare with figure 6 to see the effect of this redistribution of blood flow on gas exchange. Because ventilation is not altered, the $V^{\prime} \mathrm{A} / \mathrm{Q}^{\prime}$ ratios change such that the hypoxic region has an increased $V^{\prime} \mathrm{A} / Q^{\prime}$ ratio, increasing the $P_{\mathrm{AO}}{ }_{2}$ in that region. With more blood flow coming from the well ventilated region, with the higher $\mathrm{PAO}_{2}, \mathrm{CaO}_{2}$ and $\mathrm{PaO}_{2}$ are markedly improved. For a glossary of terms, see table $1, \mathrm{ec}$ and $\mathrm{ec}^{\star}$ denotes end-capillary blood from the two different units.

oxygenation (fig. 12). For example in humans, HPV reduces blood flow to atelectatic regions by 50\% [55, 56]; the beneficial effect on arterial oxygenation can be deduced from moving from one iso-shunt line to another at a fixed $\mathrm{FIO}_{2}$ in the iso-shunt diagram (fig. 8). The efficacy of HPV in correcting $V^{\prime} \mathrm{A} / \mathrm{Q}^{\prime}$ mismatch decreases with the extent of the hypoxic lung region $[53,57]$. One example is low $\mathrm{PAO}_{2}$ within the entire lung (e.g. due to severe hypoventilation or high altitude). In this case, generalised vasoconstriction raises pulmonary arterial pressure without improving $V^{\prime} \mathrm{A} / Q^{\prime}$ matching. Animal and human experiments indicate that HPV is of little importance for $V^{\prime} \mathrm{A} / Q^{\prime}$ matching in normal lungs $[53,58,59]$. By contrast, HPV can be of critical importance in patients with disease causing regional alveolar hypoxia [53], improving $\mathrm{PaO}_{2}$ by up to $20 \mathrm{mmHg}(2.7 \mathrm{kPa})$ in patients with COPD or ARDS [54]. An illustration of the importance of HPV is that systemically administered vasodilators, inhibiting $\mathrm{HPV}$, might reduce $\mathrm{PaO}_{2}$ in such patients [60].

\section{Supplemental oxygen and carbon dioxide retention in COPD patients}

One further illustration of the clinical importance of HPV is its role in $\mathrm{O}_{2}$-induced hypercapnia in patients with COPD. Although often attributed to a decreased drive to breathe, it has been shown that administration of supplemental $\mathrm{O}_{2}$ to these patients can increase $\mathrm{PaCO}_{2}$ despite constant minute ventilation $[61,62]$. The major explanation is that supplemental $\mathrm{O}_{2}$ raises the $P \mathrm{AO}_{2}$ in low $V^{\prime} \mathrm{A} / Q^{\prime}$ units, inhibiting regional HPV and increasing blood flow to these units. Consequently, blood is diverted away from better ventilated regions, converting them to high $V^{\prime} \mathrm{A} / Q^{\prime}$ units, which increases wasted ventilation [61, 62]. This is an illustration of how increased wasted ventilation decreases effective alveolar ventilation (discussed above), despite unchanged minute ventilation. In addition, because the low $V^{\prime} \mathrm{A} / \mathrm{Q}^{\prime}$ units have a higher $P_{A C O}$, the restored blood flow to these units results in more $\mathrm{CO}_{2}$ being delivered to the arterial blood. Increased $V^{\prime} \mathrm{A} / Q^{\prime}$ mismatch as the dominant mechanism causing $\mathrm{O}_{2}$-induced hypercapnia remains, however, controversial: other work has shown that decreased minute ventilation can contribute to increased $\mathrm{PaCO}_{2}$ [63]. One further explanation is the Haldane effect, in which increased $\mathrm{PaO}_{2}$ decreases binding of both $\mathrm{H}^{+}$and $\mathrm{CO}_{2}$ to haemoglobin, thereby increasing the amount of physically dissolved $\mathrm{CO}_{2}$ and, thus, $\mathrm{PCO}_{2}$ $[12,64]$. In other words, for any given $\mathrm{CO}_{2}$ content, $\mathrm{PCO}_{2}$ will be higher with greater haemoglobin $\mathrm{O}_{2}$ saturation. The Haldane effect has been estimated to explain $6-78 \%$ of the increase in $\mathrm{PaCO}_{2}$ in $\mathrm{COPD}$ patients after administration of supplemental $\mathrm{O}_{2}[61,65,66]$. 


\section{Inhaled vasodilators}

Inhaled vasodilators can be used to improve $V^{\prime} \mathrm{A} / \mathrm{Q}^{\prime}$ mismatch. The concept is that inhaled vasodilators are distributed to each region in proportion to regional ventilation and well ventilated regions are, therefore, more vasodilated. Locally reduced vascular tone causes a shift in blood flow away from unventilated regions toward the better ventilated regions, improving $V^{\prime} \mathrm{A} / Q^{\prime}$ matching and gas exchange. Inhaled nitric oxide has been shown to reduce shunt $[60,67]$ and improve arterial oxygenation in patients with ARDS [60, 68, 69]. A similar effect has been demonstrated with inhaled prostacyclin [70, 71]. Interestingly, the effect is less consistent in patients with COPD. In this case, inhaled nitric oxide can result in both improved and worsened gas exchange; the latter can be explained by the vasodilator also reaching low $V^{\prime} \mathrm{A} / Q^{\prime}$ regions. Inhibition of HPV increases blood flow to these low $V^{\prime} \mathrm{A} / \mathrm{Q}^{\prime}$ regions, which causes further arterial desaturation [67, 72]. The beneficial effect of inhaled nitric oxide might, therefore, be less consistent in hypoxaemia caused by low $V^{\prime} \mathrm{A} / Q^{\prime}$ regions than in conditions characterised by shunt regions.

\section{$V^{\prime} \mathrm{A} / Q^{\prime}$ mismatch in lung diseases COPD}

Patients with COPD might present with hypoxaemia, hypercapnia or both. Hypoxaemia is primarily explained by perfusion of underventilated (low $V^{\prime} \mathrm{A} / \mathrm{Q}^{\prime}$ ) regions, which has been attributed to airway disease [73-76]. Shunt is of little importance in the absence of complicating conditions such as pneumonia or atelectasis [7, 74] and hypoxaemia is, therefore, expected to respond to increased $\mathrm{FIO}_{2}$. Hypercapnia is explained by decreased effective alveolar ventilation due to increased wasted ventilation secondary to high $V^{\prime} \mathrm{A} / Q^{\prime}$ regions and alveolar dead space caused by emphysematous destruction of the lung parenchyma [73-75]. Hypercapnia becomes evident only when the patient is unable to maintain the added work of breathing required for adequate alveolar ventilation. Changes in cardiac output, $\mathrm{O}_{2}$ consumption and minute ventilation have been shown to modulate the effect of increased $V^{\prime} \mathrm{A} / Q^{\prime}$ mismatch in patients with acute COPD exacerbations [74].

\section{ARDS}

Gas exchange in patients with ARDS, often caused by pneumonia or sepsis, is characterised by severe hypoxaemia due to loss of aeration of large lung regions. Several studies have shown that arterial hypoxaemia in these patients is mostly caused by shunt blood flow that might exceed $50 \%$ of cardiac output $[13,16-19]$. Low $V^{\prime} \mathrm{A} / \mathrm{Q}^{\prime}$ regions are either absent or a lesser cause of low $\mathrm{PaO}_{2}[16,17]$. Impaired diffusion does not seem to contribute to arterial hypoxaemia [16]. The effect of PEEP on $V^{\prime} \mathrm{A} / Q^{\prime}$ mismatch in these patients is especially interesting. PEEP has been shown to reduce the amount of nonaerated lung tissue through alveolar recruitment and to improve arterial oxygenation through a decrease in shunt blood flow $[13,16,17,19,77,78]$. Increased PEEP has also been shown to increase total dead space, which is interpreted as an increased number of unperfused alveoli secondary to increased airway pressure with compression of alveolar capillaries in nondependent lung regions [16, 77-79]. The effect of PEEP on dead space is attenuated if the negative effect of PEEP on cardiac output is counteracted by fluid loading to increase cardiac preload, which also illustrates that reduced cardiac output might increase VD/VT [79]. By contrast, PEEP in combination with alveolar recruitment has been shown to decrease wasted ventilation [80]. When using PEEP to optimise gas exchange in these patients it is, thus, necessary to balance the potential beneficial and detrimental effects on oxygenation, wasted ventilation and cardiac output. Another tool to improve gas exchange in ARDS patients is treatment in the prone posture. Animal experiments and clinical studies have demonstrated that the prone posture decreases shunt and $V^{\prime} \mathrm{A} / Q^{\prime}$ mismatch, improving arterial oxygenation [81-83]. A recent clinical trial demonstrated that the use of the prone posture early in the course of ARDS was associated with improved survival [84]. The primary mechanism postulated to increase survival is not improved gas exchange, but a more uniform distribution of regional ventilation resulting in less ventilator-induced lung injury [83, 85].

\section{Pulmonary embolism}

Pulmonary embolism results in lung regions with no or reduced blood flow (high $V^{\prime} \mathrm{A} / Q^{\prime}$ regions) and, thus, increased wasted ventilation. Less obviously, redistribution of blood flow to other lung regions causes these regions to become relatively overperfused, and transformed into low $V^{\prime} \mathrm{A} / Q^{\prime}$ regions, creating hypoxaemia and an increased $\mathrm{PA}-\mathrm{aO}_{2}$. The reason for hypoxaemia is, thus, increased $V^{\prime} \mathrm{A} / Q^{\prime}$ mismatch but not increased shunt $[86,87]$. The effect on ABGs is modified by the respiratory response to increased $P_{a C O}$, the end result often being a dyspnoeic patient with hypoxaemia and normal or even low $\mathrm{PaCO}_{2}$. Hypoxaemia might be aggravated by circulatory failure causing low $\mathrm{C}_{\overline{\mathrm{v}}} \mathrm{O}_{2}$ or by intracardiac right-to-left shunting, both provoked by acute pulmonary hypertension. Importantly, the absence of hypoxaemia or increased $\mathrm{PA}_{\mathrm{a}} \mathrm{aO}$ does not rule out pulmonary embolism $[88,89]$. Similarly, using the $\mathrm{PaCO}_{2}-\mathrm{PETCO}_{2}$ to gauge wasted ventilation is informative, but in isolation is not definitive for diagnosing pulmonary embolism [90]. While 
a $\mathrm{PETCO}_{2}$ measurement indicating increased wasted ventilation increases the likelihood of pulmonary embolism [91] and a normal amount of wasted ventilation diminishes the likelihood [33, 92], the utility of these measures is very dependent on the a priori clinical probability of pulmonary embolism in the individual patient [90] and the fraction of the pulmonary vascular tree that is involved [91].

\section{Summary}

1) There are five cause of hypoxaemia. Decreased $\mathrm{PaO}_{2}$ can be caused by hypoventilation, low $\mathrm{PIO}_{2}$, diffusion limitation, low $V^{\prime} \mathrm{A} / Q^{\prime}$ regions or shunt. In contrast with other causes, hypoxaemia due to shunt characteristically responds poorly to increased $\mathrm{FIO}_{2}$. Low $V^{\prime} \mathrm{A} / Q^{\prime}$ regions and shunt are by far the most common causes of clinically encountered hypoxaemia.

2) Hypoventilation and low $V^{\prime} \mathrm{A} / Q^{\prime}$ regions also impair $\mathrm{CO}_{2}$ removal, but the magnitude of the effect on $\mathrm{PaCO}_{2}$ is less and modified by the ventilatory response to hypercapnia.

3) High $V^{\prime} \mathrm{A} / Q^{\prime}$ regions and alveolar and apparatus dead space cause increased wasted ventilation and, thus, impaired $\mathrm{CO}_{2}$ elimination. The primary response to increased wasted ventilation is, in most situations, increased minute ventilation and work of breathing, not increased $\mathrm{PaCO}_{2}$.

4) The effect of $V^{\prime} \mathrm{A} / Q^{\prime}$ mismatch on gas exchange efficiency can be quantified using calculations of $P \mathrm{~A}-\mathrm{aO}_{2}$, venous admixture and wasted ventilation.

5) Low and high $V^{\prime} \mathrm{A} / Q^{\prime}$ regions cause hypoxaemia, impaired $\mathrm{CO}_{2}$ elimination and increased work of breathing in COPD patients.

6) Shunt is the most important cause of hypoxaemia in patients with ARDS and pneumonia.

\section{References}

1 Gehr P, Bachofen M, Weibel ER. The normal human lung: ultrastructure and morphometric estimation of diffusion capacity. Respir Physiol 1978; 32: 121-140.

2 Weibel ER, Federspiel WJ, Fryder-Doffey F, et al. Morphometric model for pulmonary diffusing capacity. I. Membrane diffusing capacity. Respir Physiol 1993; 93: 125-149.

Weibel ER. What makes a good lung? Swiss Med Wkly 2009; 139: 375-386.

4 Prefaut C, Durand F, Mucci P, et al. Exercise-induced arterial hypoxaemia in athletes: a review. Sports Med 2000; 30: 47-61.

Dempsey JA, Wagner PD. Exercise-induced arterial hypoxemia. J Appl Physiol 1999; 87: 1997-2006.

6 Hopkins SR. Exercise induced arterial hypoxemia: the role of ventilation-perfusion inequality and pulmonary diffusion limitation. Adv Exp Med Biol 2006; 588: 17-30.

7 Agustí AGN, Barberà JA. Contributions of multiple inert gas elimination technique to pulmonary medicine 2. Chronic pulmonary diseases: chronic obstructive pulmonary disease and idiopathic pulmonary fibrosis. Thorax 1994; 49: 924-932.

8 Rahn H. A concept of mean alveolar air and the ventilation-blood flow relationships during pulmonary gas exchange. Am J Physiol 1949; 158: 21-30.

9 Riley RL, Cournand A. Ideal alveolar air and the analysis of ventilation-perfusion relationships in the lungs. J Appl Physiol 1949; 1: 825-847.

10 West JB. State of the art: ventilation-perfusion relationships. Am Rev Respir Dis 1977; 116: 919-943.

11 Grocott MP, Martin DS, Levett DZ, et al. Arterial blood gases and oxygen content in climbers on Mount Everest. N Engl J Med 2009; 360: 140-149.

12 Lumb AB. Nunn's Applied Respiratory Physiology. 5th Edn. Oxford, Butterworth-Heinemann, 2000.

13 Dantzker DR, Lynch JP, Weg JG. Depression of cardiac output is a mechanism of shunt reduction in the therapy of acute respiratory failure. Chest 1980; 77: 636-642.

14 Takala J. Hypoxemia due to increased venous admixture: influence of cardiac output on oxygenation. Intensive Care Med 2007; 33: 908-911.

15 Benatar SR, Hewlett AM, Nunn JF. The use of iso-shunt lines for control of oxygen therapy. Br J Anaesth 1973; 45: 711-718.

16 Dantzker DR, Brook CJ, Dehart P, et al. Ventilation-perfusion distributions in the adult respiratory distress syndrome. Am Rev Respir Dis 1979; 120: 1039-1052.

17 Pesenti A, Riboni A, Marcolin R, et al. Venous admixture (Qva/Q) and true shunt (Qs/Qt) in ARF patients: effects of PEEP at constant $\mathrm{FIO}_{2}$. Intensive Care Med 1983; 9: 307-311.

18 Dakin J, Jones AT, Hansell DM, et al. Changes in lung composition and regional perfusion and tissue distribution in patients with ARDS. Respirology 2011; 16: 1265-1272.

19 Ralph DD, Robertson HT, Weaver LJ, et al. Distribution of ventilation and perfusion during positive endexpiratory pressure in the adult respiratory distress syndrome. Am Rev Respir Dis 1985; 131: 54-60.

20 Enghoff H. Volumen inefficax. Bemerkungen zur Frage des schädlichen Raumes. Uppsala Lak Forhandl 1938; 44: 191-218.

21 Hedenstierna G, Sandhagen B. Assessing dead space. A meaningful variable? Minerva Anestesiol 2006; 72: 521-528.

22 Wagner PD, Laravuso RB, Uhl RR, et al. Continuous distributions of ventilation-perfusion ratios in normal subjects breathing air and 100 per cent $\mathrm{O}_{2}$. J Clin Invest 1974; 54: 54-68.

23 Tusman G, Sipmann FS, Borges JB, et al. Validation of Bohr dead space measured by volumetric capnography. Intensive Care Med 2011; 37: 870-874.

24 Fletcher R, Jonson B. Prediction of the physiological dead space/tidal volume ratio during anaesthesia/IPPV from simple pre-operative tests. Acta Anaesthesiol Scand 1981; 25: 58-62. 
ones NL, Robertson DG, Kane JW. Difference between end-tidal and arterial $\mathrm{PCO}_{2}$ in exercise. J Appl Physiol Respir Environ Exerc Physiol 1979; 47: 954-960.

26 Benallal H, Busso T. Analysis of end-tidal and arterial $\mathrm{PCO}_{2}$ gradients using a breathing model. Eur J Appl Physiol 2000; 83: 402-408.

27 Dubois AB, Britt AG, Fenn WO. Alveolar $\mathrm{CO}_{2}$ during the respiratory cycle. I Appl Physiol 1952; 4: 535-548.

28 Severinghaus JW, Stupfel M. Alveolar dead space as an index of distribution of blood flow in pulmonary capillaries. J Appl Physiol 1957; 10: 335-348.

29 Hardman JG, Aitkenhead AR. Estimation of alveolar deadspace fraction using arterial and end-tidal $\mathrm{CO}_{2}$ : a factor analysis using a physiological simulation. Anaesth Intensive Care 1999; 27: 452-458.

30 Hardman JG, Aitkenhead AR. Estimating alveolar dead space from the arterial to end-tidal $\mathrm{CO}_{2}$ gradient: a modeling analysis. Anesth Analg 2003; 97: 1846-1851.

31 Kirby RR. Capnography and respiratory assessment outside of the operating room. In: Gravenstein JS, Jaffe MB, Gravenstein N, et al. eds. Capnography. 2nd Edn. Cambridge, Cambridge University Press, 2011; pp. 11-18.

32 Nunn JF, Hill DW. Respiratory dead space and arterial to end-tidal carbon dioxide tension difference in anesthetized man. J Appl Physiol 1960; 15: 383-389.

33 Hemnes AR, Newman AL, Rosenbaum B, et al. Bedside end-tidal $\mathrm{CO}_{2}$ tension as a screening tool to exclude pulmonary embolism. Eur Respir J 2010; 35: 735-741.

34 Tusman G, Suarez-Sipmann F, Bohm SH, et al. Capnography reflects ventilation/perfusion distribution in a model of acute lung injury. Acta Anaesthesiol Scand 2011; 55: 597-606.

35 Glenny RW. Determinants of regional ventilation and blood flow in the lung. Intensive Care Med 2009; 35: 1833-1842.

36 Glenny RW, Lamm WJ, Albert RK, et al. Gravity is a minor determinant of pulmonary blood flow distribution. J Appl Physiol 1991; 71: 620-629.

37 Glenny RW, Bernard S, Robertson HT, et al. Gravity is an important but secondary determinant of regional pulmonary blood flow in upright primates. J Appl Physiol 1999; 86: 623-632.

38 West JB, Dollery CT, Naimark A. Distribution of blood flow in isolated lung; relation to vascular and alveolar pressures. J Appl Physiol 1964; 19: 713-724.

39 Hlastala MP, Glenny RW. Vascular structure determines pulmonary blood flow distribution. News Physiol Sci 1999; 14: 182-186.

40 Glenny RW, Polissar L, Robertson HT. Relative contribution of gravity to pulmonary perfusion heterogeneity. J Appl Physiol 1991; 71: 2449-2452.

41 Glenny RW, Robertson HT. Fractal properties of pulmonary blood flow: characterization of spatial heterogeneity. J Appl Physiol 1990; 69: 532-545.

42 Petersson J, Rohdin M, Sánchez-Crespo A, et al. Regional lung blood flow and ventilation in upright humans studied with quantitative SPECT. Respir Physiol Neurobiol 2009; 166: 54-60.

43 West JB. Regional differences in gas exchange in the lung of erect man. J Appl Physiol 1962; 17: 893-898.

44 Janssens JP, Pache JC, Nicod LP. Physiological changes in respiratory function associated with ageing. Eur Respir J 1999; 13: 197-205.

45 Hardie JA, Vollmer WM, Buist AS, et al. Reference values for arterial blood gases in the elderly. Chest 2004; 125: 2053-2060.

46 Crapo RO, Jensen RL, Hegewald M, et al. Arterial blood gas reference values for sea level and an altitude of 1,400 meters. Am J Respir Crit Care Med 1999; 160: 1525-1531.

47 Mellemgaard K. The alveolar-arterial oxygen difference: its size and components in normal man. Acta Physiol Scand 1966; 67: 10-20.

48 Harris EA, Kenyon AM, Nisbet HD, et al. The normal alveolar-arterial oxygen-tension gradient in man. Clin Sci Mol Med 1974; 46: 89-104

49 Aboab J, Louis $\mathrm{B}$, Jonson $\mathrm{B}$, et al. Relation between $\mathrm{PaO}_{2} / \mathrm{FIO}_{2}$ ratio and $\mathrm{FIO}_{2}$ : a mathematical description. Intensive Care Med 2006; 32: 1494-1497.

50 Gowda MS, Klocke RA. Variability of indices of hypoxemia in adult respiratory distress syndrome. Crit Care Med 1997; 25: 41-45.

51 Von Euler U, Liljestrand G. Observations on the pulmonary arterial blood pressure in the cat. Acta Physiol Scand 1946; 12: 301-320.

Moudgil R, Michelakis ED, Archer SL. Hypoxic pulmonary vasoconstriction. J Appl Physiol 2005; 98: 390-403.

Sylvester JT, Shimoda LA, Aaronson PI, et al. Hypoxic pulmonary vasoconstriction. Physiol Rev 2012; 92: 367-520. Naeije R, Brimioulle S. Physiology in medicine: importance of hypoxic pulmonary vasoconstriction in maintaining arterial oxygenation during acute respiratory failure. Crit Care 2001; 5: 67-71.

55 Morrell NW, Nijran KS, Biggs T, et al. Magnitude and time course of acute hypoxic pulmonary vasoconstriction in man. Respir Physiol 1995; 100: 271-281.

56 Morrell NW, Nijran KS, Biggs T, et al. Regional matching of ventilation and perfusion during lobar bronchial occlusion in man. Clin Sci (Lond) 1995; 88: 179-184.

57 Marshall BE, Marshall C, Benumof J, et al. Hypoxic pulmonary vasoconstriction in dogs: effects of lung segment size and oxygen tension. J Appl Physiol 1981; 51: 1543-1551.

58 Arai TJ, Henderson AC, Dubowitz DJ, et al. Hypoxic pulmonary vasoconstriction does not contribute to pulmonary blood flow heterogeneity in normoxia in normal supine humans. J Appl Physiol 2009; 106: 1057-1064.

59 Frostell CG, Blomqvist H, Hedenstierna G, et al. Inhaled nitric oxide selectively reverses human hypoxic pulmonary vasoconstriction without causing systemic vasodilation. Anesthesiology 1993; 78: 427-435.

60 Rossaint R, Falke KJ, López F, et al. Inhaled nitric oxide for the adult respiratory distress syndrome. $N$ Engl J Med 1993; 328: 399-405.

61 Aubier M, Murciano D, Milic-Emili J, et al. Effects of the administration of $\mathrm{O}_{2}$ on ventilation and blood gases in patients with chronic obstructive pulmonary disease during acute respiratory failure. Am Rev Respir Dis 1980; 122: 747-754.

62 Sassoon CS, Hassell KT, Mahutte CK. Hyperoxic-induced hypercapnia in stable chronic obstructive pulmonary disease. Am Rev Respir Dis 1987; 135: 907-911. 
63 Robinson TD, Freiberg DB, Regnis JA, et al. The role of hypoventilation and ventilation-perfusion redistribution in oxygen-induced hypercapnia during acute exacerbations of chronic obstructive pulmonary disease. Am J Respir Crit Care Med 2000; 161: 1524-1529.

64 Christiansen J, Douglas CG, Haldane JS. The absorption and dissociation of carbon dioxide by human blood. J Physiol 1914; 48: 244-271.

65 Feller-Kopman D, Schwartzstein R. The role of hypoventilation and ventilation-perfusion redistribution in oxygeninduced hypercapnia during acute exacerbations of chronic obstructive pulmonary disease (correspondence). Am J Respir Crit Care Med 2001; 163: 1755.

66 Luft UC, Mostyn EM, Loeppky JA, et al. Contribution of the Haldane effect to the rise of arterial $P_{\mathrm{CO}_{2}}$ in hypoxic patients breathing oxygen. Crit Care Med 1981; 9: 32-37.

67 Hopkins SR, Johnson EC, Richardson RS, et al. Effects of inhaled nitric oxide on gas exchange in lungs with shunt or poorly ventilated areas. Am J Respir Crit Care Med 1997; 156: 484-491.

68 Blanch L, Joseph D, Fernández R, et al. Hemodynamic and gas exchange responses to inhalation of nitric oxide in patients with the acute respiratory distress syndrome and in hypoxemic patients with chronic obstructive pulmonary disease. Intensive Care Med 1997; 23: 51-57.

69 Griffiths MJ, Evans TW. Inhaled nitric oxide therapy in adults. N Engl J Med 2005; 353: 2683-2695.

70 Walmrath D, Schneider T, Schermuly R, et al. Direct comparison of inhaled nitric oxide and aerosolized prostacyclin in acute respiratory distress syndrome. Am J Respir Crit Care Med 1996; 153: 991-996.

71 Zwissler B, Kemming G, Habler O, et al. Inhaled prostacyclin (PGI2) versus inhaled nitric oxide in adult respiratory distress syndrome. Am J Respir Crit Care Med 1996; 154: 1671-1677.

72 Barberà JA, Roger N, Roca J, et al. Worsening of pulmonary gas exchange with nitric oxide inhalation in chronic obstructive pulmonary disease. Lancet 1996; 347: 436-440.

73 Wagner PD, Dantzker DR, Dueck R, et al. Ventilation-perfusion inequality in chronic obstructive pulmonary disease. J Clin Invest 1977; 59: 203-216.

74 Barberà JA, Roca J, Ferrer A, et al. Mechanisms of worsening gas exchange during acute exacerbations of chronic obstructive pulmonary disease. Eur Respir J 1997; 10: 1285-1291.

75 Diaz O, Iglesia R, Ferrer M, et al. Effects of noninvasive ventilation on pulmonary gas exchange and hemodynamics during acute hypercapnic exacerbations of chronic obstructive pulmonary disease. Am J Respir Crit Care Med 1997; 156: $1840-1845$.

76 Young IH, Bye PT. Gas exchange in disease: asthma, chronic obstructive pulmonary disease, cystic fibrosis, and interstitial lung disease. Compr Physiol 2011; 1: 663-697.

77 Matamis D, Lemaire F, Harf A, et al. Redistribution of pulmonary blood flow induced by positive end-expiratory pressure and dopamine infusion in acute respiratory failure. Am Rev Respir Dis 1984; 129: 39-44.

78 Suter PM, Fairley B, Isenberg MD. Optimum end-expiratory airway pressure in patients with acute pulmonary failure. N Engl J Med 1975; 292: 284-289.

79 Hedenstierna G, White FC, Mazzone R, et al. Redistribution of pulmonary blood flow in the dog with PEEP ventilation. J Appl Physiol 1979; 46: 278-287.

80 Tusman G, Suarez-Sipmann F, Böhm SH, et al. Monitoring dead space during recruitment and PEEP titration in an experimental model. Intensive Care Med 2006; 32: 1863-1871.

81 Lamm WJ, Graham MM, Albert RK. Mechanism by which the prone position improves oxygenation in acute lung injury. Am J Respir Crit Care Med 1994; 150: 184-193.

82 Mure M, Martling CR, Lindahl SG. Dramatic effect on oxygenation in patients with severe acute lung insufficiency treated in the prone position. Crit Care Med 1997; 25: 1539-1544.

83 Richter T, Bellani G, Scott Harris R, et al. Effect of prone position on regional shunt, aeration, and perfusion in experimental acute lung injury. Am J Respir Crit Care Med 2005; 172: 480-487.

84 Guérin C, Reignier J, Richard JC. Prone positioning in the acute respiratory distress syndrome. N Engl J Med 2013; 369: 980-981.

85 Galiatsou E, Kostanti E, Svarna E, et al. Prone position augments recruitment and prevents alveolar overinflation in acute lung injury. Am J Respir Crit Care Med 2006; 174: 187-197.

86 Santolicandro A, Prediletto R, Fornai E, et al. Mechanisms of hypoxemia and hypocapnia in pulmonary embolism. Am J Respir Crit Care Med 1995; 152: 336-347.

87 Altemeier WA, Robertson HT, McKinney S, et al. Pulmonary embolization causes hypoxemia by redistributing regional blood flow without changing ventilation. J Appl Physiol 1998; 85: 2337-2343.

88 Deutsch AB, Twitty P, Downes K, et al. Assessment of the alveolar-arterial oxygen gradient as a screening test for pulmonary embolism in pregnancy. Am J Obstet Gynecol 2010; 203: 373 el-e4.

89 Rodger MA, Carrier M, Jones GN, et al. Diagnostic value of arterial blood gas measurement in suspected pulmonary embolism. Am J Respir Crit Care Med 2000; 162: 2105-2108.

90 Manara A, D'Hoore W, Thys F. Capnography as a diagnostic tool for pulmonary embolism: a meta-analysis. Ann Emerg Med 2013; 62: 584-591.

91 Kline JA, Hogg MM, Courtney DM, et al. D-dimer and exhaled $\mathrm{CO}_{2} / \mathrm{O}_{2}$ to detect segmental pulmonary embolism in moderate-risk patients. Am J Respir Crit Care Med 2010; 182: 669-675.

92 Rodger MA, Jones G, Rasuli P, et al. Steady-state end-tidal alveolar dead space fraction and D-dimer: bedside tests to exclude pulmonary embolism. Chest 2001; 120: 115-119. 